\title{
Application of New and Novel Fracture Stimulation Technologies To Enhance the Deliverability of Gas Storage Wells
}

Topical Report

April 1995
R :

SEP U h in.

0.5 .1

April 1995

Work Performed Under Contract No.: DE-FC21-94MC31112

For

U.S. Department of Energy

Office of Fossil Energy

Morgantown Energy Technology Center

Morgantown, West Virginia

By

Advanced Resources International

1110 North Glebe Road, Suite 600

Arlington, Virginia 22201 


\section{DISCLAIMER}

Portions of this document may be illegible in electronic image products. Images are produced from the best available original document. 


\section{DISCLAIMER}

This report was prepared as an account of work sponsored by an agency of the United States Government. Neither the United States Government nor any agency thereof, nor any of their employees, makes any warranty, express or implied, or assumes any legal liability or responsibility for the accuracy, completeness, or usefulness of any information, apparatus, product, or process disclosed, or represents that its use would not infringe privately owned rights. Reference herein to any specific commercial product, process, or service by trade name, trademark, manufacturer, or otherwise does not necessarily constitute or imply its endorsement, recommendation, or favoring by the United States Government or any agency thereof. The views and opinions of authors expressed herein do not necessarily state or reflect those of the United States Government or any agency thereof.

Available to the public from the National Technical Information Service, U.S. Department of Commerce, 5285 Port Royal Road, Springfield, VA 22161; phone orders accepted at (703) 487-4650.

This report has been reproduced directly from the best available copy. 


\section{Application of New and Novel Fracture Stimulation Technologies to Enhance the Deliverability of Gas Storage Wells}

\section{Topical Report \\ April 1995}

Work Performed Under Contract No.: DE-FC21-94MC31112

\section{For}

U.S. Department of Energy

Office of Fossil Energy

Morgantown Energy Technology Center

P.O. Box 880

Morgantown, West Virginia 26507-0880

\section{By}

Advanced Resources International

1110 North Glebe Road, Suite 600

Arlington, Virginia 22201 


\section{Table of Contents}

Page

Executive Summary $\ldots \ldots \ldots \ldots \ldots \ldots \ldots \ldots \ldots \ldots \ldots \ldots$

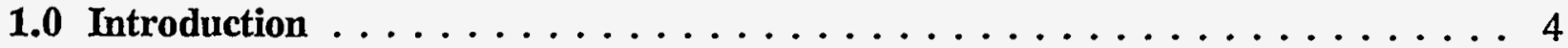

2.0 Description of New and Novel Fracturing Technologies $\ldots \ldots \ldots \ldots \ldots$

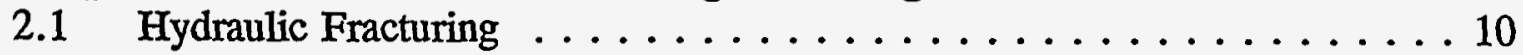

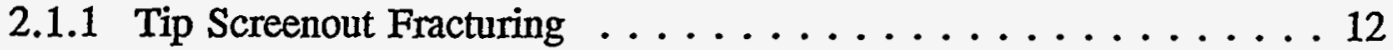

2.1.2 Fracturing with Liquid Carbon Dioxide $\ldots \ldots \ldots \ldots \ldots \ldots$

2.1.3 Fracturing with Nitrogen $\ldots \ldots \ldots \ldots \ldots \ldots \ldots \ldots \ldots \ldots$

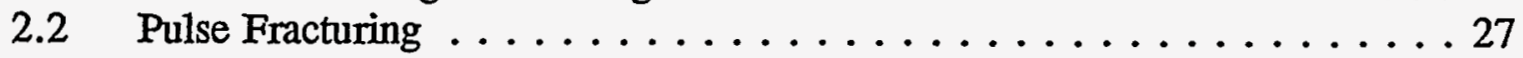

2.2.1 Propellent Fracturing . . . . . . . . . . . . . 27

2.2.2 Pulse Fracturing with Nitrogen $\ldots \ldots \ldots \ldots \ldots \ldots \ldots$

3.0 Review of Recent Fracturing Experience in the Gas Storage Industry . . . . . 39

3.1 Overview of Remediation Activity . . . . . . . . . . . . 39

3.2 Non-Fracturing Remediation Case Studies ... . . . . . . . . 40

3.3 Fracturing Case Study in the Gas Storage Industry . . . . . . . . 44

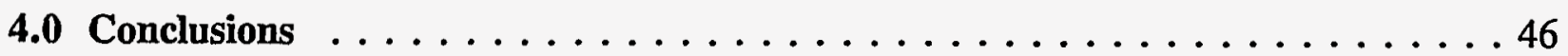

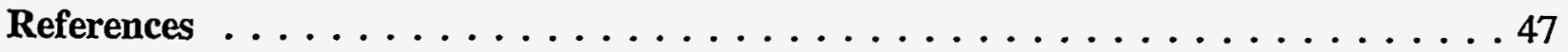




\section{List of Figures}

Page

Figure 1 Comparison of Pressure Histories for Rock Fracturing

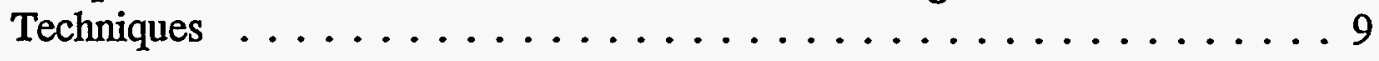

Figure 2 Comparison of Created Fracture Geometries for Rock Fracturing Techniques $\ldots \ldots \ldots \ldots \ldots \ldots \ldots$

Figure $3 \quad$ Schematic of Hydraulic Fracture $\ldots \ldots \ldots \ldots \ldots \ldots \ldots$

Figure $4 \quad$ Schematic View of a Tip-Screenout $\ldots \ldots \ldots \ldots \ldots$

Figure 5 Sequence of the Tip-Screenout Fracture Treatment $\ldots \ldots \ldots \ldots 14$

Figure $6 \quad$ Liquid Carbon Dioxide Blender . . . . . . . . . . . . 19

Figure 7 Liquid Carbon Dioxide Stimulation Equipment Layout . . . . . . . 20

Figure $8 \quad$ Liquid Carbon Dioxide Fracturing Study Area $\ldots \ldots \ldots \ldots \ldots$

Figure 9 Comparison of Production Results When Fracturing with Nitrogen . . . 26

Figure 10 Conceptual Model of Pulse Fracturing Results $\ldots \ldots \ldots \ldots$

Figure 11 Idealized Pressure History for Propellant Fracturing . . . . . . . . 29

Figure 12 Fracture Pattern from a Single Mineback Experiment $\ldots \ldots \ldots 33$

Figure 13 Fracture Patterns from Multiple Mineback Experiments $\ldots \ldots \ldots \ldots 33$

Figure 14 Production Increases Resulting from HEGF Treatments in the South Beldridge Field . . . . . . . . . . . . . 34 


\section{List of Tables}

Page

Table 1 Formation Fractured with Liquid Carbon Dioxide (through 1987) . . . . 21

Table 2 Production Results from Liquid Carbon Dioxide

Fracturing Case Study $\ldots \ldots \ldots \ldots \ldots \ldots \ldots \ldots \ldots \ldots$

Table 3 Stimulation Results for the Meigs County Site . . . . . . . . . 31

Table 4 Pre- and Post-Stimulation Production at

the Empire and Ibelin Fields $\ldots \ldots \ldots \ldots \ldots \ldots \ldots \ldots$

Table $5 \quad$ Pre- and Post-Propellant Skin Factors from East Lake Erie . . . . . . . 35

Table $6 \quad$ Results of Oryx Energy Nitrogen Pulse Fracturing Program . . . . . 38

Table $7 \quad$ Summary of Storage Well Remediation Activity . . . . . . . . . . 39

Table $8 \quad$ Storage Well Remediation Activity by Company $\ldots \ldots \ldots \ldots$

Table $9 \quad$ Field A Remediation Results $\ldots \ldots \ldots \ldots \ldots \ldots$

Table $10 \quad$ Field B Remediation Results . . . . . . . . . . . . . . . 42

Table $11 \quad$ Case 2 Remediation Results $\ldots \ldots \ldots \ldots \ldots \ldots \ldots \ldots$

Table 12 CNG Transmission Gas Storage Fields Where Fracturing

Was Utilized in $1994 \ldots \ldots \ldots \ldots \ldots \ldots \ldots$. . . . . . . . . 44

Table $13 \quad$ Results of Fracture Stimulation Treatments . . . . . . . . . 45 


\section{Executive Summary}

An improved, more efficient natural gas transmission and deliverability system will be essential for supporting the expected growth in U.S. gas demand in the coming decades. The role of gas storage in this system will be particularly important as much of the new natural gas use will be cyclic in nature, coming from the residential sector of the north-east with high winter season gas needs, and from new power generation facilities throughout the U.S. with high peakday requirements. The most cost-effective means for providing this additional seasonal capacity and peak-day deliverability is to improve the efficiency of the existing gas storage system.

A high priority thus exists to improve the efficiency of the 370 gas storage facilities and the 17,000 existing gas storage wells. These facilities and wells currently contain almost 4 Tcf of working gas, $24 \mathrm{Bcf}$ per day of seasonal capability and 54 Bcf per day of peak-day deliverability. The goal is to increase current capability, and, importantly, to counteract the persistent $5.2 \%$ loss in annual well deliverability that is being observed by industry.

With these annual deliverability losses, it is now obvious to most gas storage operators that many wells are not physically performing up to their deliverability potential, but they currently do not have an entirely effective solution to this problem. Industry's current deliverability enhancement techniques focus largely on simple well remediation methods as well as more expensive infill drilling. The typical remediation treatment involves cleaning the wellbore by mechanical means or by blowing/washing, acidizing, and/or re-perforating. Field evidence suggests that these treatments, at best, only temporarily restore well deliverability. As a result, costly infill drilling is the primary approach to offset the decline in gas storage deliverability, which requires annual capital expenditures of $\$ 65$ to $\$ 70$ million and does nothing to improve the condition of existing wells. Alternative, more effective and durable stimulation methods for existing wells therefore have the potential to significantly lower these deliverability maintenance costs.

The attributes of an improved remediation treatment in a gas storage well would include the creation of new, conductive flow paths that would be less susceptible to fines plugging and 
damage, that would reduce near-wellbore pressure drops to mitigate fines mobilization and scale disposition, and that would extend beyond the extent of current damage. Such a technique would not only stimulate well deliverability, as compared to merely reducing the damage effect, but due to its deeper penetration and highly conductive flowpath, would also maintain well deliverability for longer periods of time.

Fracturing technologies, now routinely employed in the oil and gas production industry as a means of stimulating well performance, possess these important attributes. These technologies have received limited utilization by the gas storage industry because of concerns that the created fractures may penetrate the reservoir seal and promote gas leakage and probably also to some extent the higher initial cost. Through the utilization of advanced treatment design and implementation procedures, however, these methods can be safely applied to gas storage reservoirs, especially since the treatments would be small in size, only to get past the near-well damaged zone.

Some operators have already begun to demonstrate the effectiveness of fracturing as a well revitalization method. As one example, CNG Transmission hydraulically fractured 30 wells in five of their gas storage fields in Pennsylvania and New York during 1994. The wells responded with over a five-fold improvement in short-term deliverability, as compared to a 2-3 fold improvement for the more traditional approaches.

The economic impact of successfully implementing these new well revitalization techniques to the gas storage industry would be substantial. If the average decline rate of storage well deliverability could be cut by one-third, from $5.2 \%$ to $3.5 \%$ per year (by effectively fracturing existing wells), such that infill well drilling could be curtailed, the industry would save one-half to two-thirds: of what it currently spends offsetting deliverability decline, translating into a savings of $\$ 20-25$ million per year. Hence a substantial RD\&D opportunity exists to promote and accelerate the transfer of this technology.

DOE/METC has responded to this industry priority and RD\&D opportunity by recognizing it in their Natural Gas Plan and by initiating this major, multi-year field 
demonstration program designed to demonstrate the application of fracturing to revitalize deliverability from existing gas storage facilities and wells. The program's key features are in its broad consideration of various new and novel fracturing technologies and its joint effort with and co-funding by industry. Nine separate field projects consisting of three new and novel fracture stimulation treatments at each project site will be selected from a set of technologies that include: (1) tip-screenout hydraulic fracturing; (2) fracturing with liquid carbon dioxide; (3) fracturing with nitrogen; (4) propellant fracturing; and (5) pulse fracturing with nitrogen. These particular technologies were selected for testing because of their appropriateness as damage removal treatments in high permeability formations (tip-screenout, proppellant and pulse fracturing), as well as for their non-damaging characteristics (liquid $\mathrm{CO}_{2}$ and nitrogen fracturing). 


\subsection{Introduction}

An improved, more efficient natural gas transmission and deliverability system will be essential for supporting the expected growth in U.S. gas demand in the coming decades. The role of gas storage in this system will be particularly important as much of the new natural gas use will be cyclic in nature, coming from the residential sector of the north-east with high winter season gas needs, and from new power generation facilities throughout the U.S. with high peakday requirements. The most cost-effective means for providing this additional seasonal storage capacity and peak-day deliverability is to improve the efficiency of the existing gas storage system. Recognizing the economic realities of FERC Order 636 and an unbundled storage system, the National Petroleum Council clearly set forth industry's views on this issue when they stated:

The first step in reducing costs is "minimizing new facility requirements through the more efficient use of existing facilities and the utilization of new technology. "1

Thus a high priority is to improve the efficiency of the $\mathbf{3 7 0}$ gas storage facilities and the 17,000 existing gas storage wells. These facilities and wells currently contain almost $4 \mathrm{Tcf}$ of working gas, 24 Bcf per day of seasonal capability and 54 Bcf per day of peak-day deliverability. ${ }^{2}$ The goal is to increase current capability, and, importantly, to counteract the persistent $5.2 \%$ loss in annual well deliverability that is being observed by industry ${ }^{3}$.

With these annual deliverability losses, it is now obvious to most gas storage operators that many wells are not physically performing up to their deliverability potential, but they currently do not have an entirely effective solution to this problem. Industry's current deliverability enhancement techniques focus largely on simple well remediation methods and infill drilling, the latter of which does nothing to improve the existing wells. The typical remediation treatment involves cleaning the wellbore by mechanical means or by blowing/washing, acidizing, and/or re-perforating. Field evidence suggests that these treatments, at best, only temporarily restore well deliverability. As a result, costly infill drilling is the primary approach to offset the decline in gas storage deliverability, which requires annual capital 
expenditures of $\$ 65$ to $\$ 70$ million $^{3}$. Alternative, more effective and durable stimulation methods therefore have the potential to significantly lower these deliverability maintenance costs.

Because of cyclic and reversible nature of their operation, gas storage wells are exposed to contamination beyond that of a normal gas production well. Most formation damage that occurs in gas storage wells is concentrated in the near-wellbore region. Damage caused by production can be related to the high pressure drops that occur in this region during periods of peak deliverability during periods of high demand; formation fines are mobilized and plug the pore spaces near the well, salts and scales are deposited as a result of the rapid pressure drop over a short radial distance, and wellbore sloughing can even occur, which can block the wellbore. Injection of gas also presents a variety of damage mechanisms. The sandface performs as a filter for any atomized compressor oil or particulate matter originating from the surface and/or the casing, and dry gas injection can also alter the wettability characteristics of a storage reservoir, potentially mobilizing formation fines.

The well revitalization techniques used today in the gas storage industry, namely blowing/washing, mechanical cleaning of the wellbore, acidizing and reperforating have, by their very nature, only limited depths of influence into the formation for damage treatment, probably no more than a few feet. These methods may serve to remove or bypass some of the damage, however experience has shown that effective well stimulation is not achieved, and any improvement in observed deliverability will begin to decline almost immediately as the same damage mechanisms reoccur. This is probably because the flow path system through the nearwellbore region remains essentially unaltered, i.e., gas and particulate matter must still travel through a network of reservoir pore throats. Furthermore, the current methods may not penetrate deeply enough into the storage reservoir, leaving a damaged region intact beyond the radius of influence of the treatment.

Considering this information, attributes of an improved remediation treatment in a gas storage well would include the creation of new, conductive flow paths that would be less susceptible to fines plugging and damage, that would reduce near-wellbore pressure drops to mitigate fines mobilization and scale disposition, and that would extend beyond current damage. 
Such a technique would not only stimulate well deliverability, as compared to merely reducing the damage effect, but due to its deeper penetration and highly conductive flowpath, would also maintain well deliverability at higher rates for longer periods of time.

Fracturing technologies, now routinely employed in the oil and gas production industry as a means of stimulating well performance, possess these important attributes. These technologies have received limited utilization by the gas storage industry because of concerns that the created fractures may penetrate the reservoir seal and promote gas leakage. Through the utilization and advanced treatment design and implementation procedures, however, these methods can be safely applied to gas storage reservoirs. This is aided by the fact that the fractures only need to penetrate beyond the near-well damaged zone, and thus smaller jobs can be conducted limiting the chance for uncontrolled height growth.

The economic impact of successfully implementing these well revitalization techniques to the gas storage industry would be substantial. If the average decline rate of storage well deliverability could be cut by one-third, from $5.2 \%$ to $3.5 \%$ per year (by effectively fracturing existing wells), such that infill well drilling could be curtailed, the industry would save one-half to two-thirds of what it currently spends offsetting deliverability decline, translating into a savings of $\$ 20-25$ million per year. Hence a substantial RD\&D opportunity exists to promote and accelerate the transfer of this technology.

DOE/METC has responded to this industry priority and RD\&D opportunity by recognizing it in their Natural Gas Plan and by initiating this major, multi-year field demonstration program designed to demonstrate the application of fracturing to revitalize deliverability from existing gas storage facilities and wells. The program's key features are in its broad consideration of various new and novel fracturing technologies and its joint effort with and co-funding by industry. Nine separate field projects consisting of three new and novel fracture stimulation treatments at each project site will be selected from a set of technologies that include: (1) tip screenout hydraulic fracturing; (2) hydraulic fracturing with liquid carbon dioxide; (3) hydraulic fracturing with nitrogen; (4) propellant fracturing; and (5) pulse fracturing with nitrogen. The purpose of this report is to describe each of these new and novel fracturing 
technologies that are being investigated as part of this DOE/METC RD\&D project, and to present some of the recent storage industry experience with fracturing, particularly as it compares to the traditionally utilized remediation approaches in terms of deliverability enhancement. 


\subsection{Description of New and Novel Fracturing Technologies}

Fracture stimulation technologies for enhancing well deliverability can generally be categorized according to the rate at which energy is applied to the target horizon to induce fracturing. As shown in Figures 1 and 2(a), at one extreme, hydraulic fracturing involves a relatively low rate of loading, resulting in a two-winged vertical fracture extending outward from a well, approximately $180^{\circ}$ apart and oriented perpendicular to the least principal rock stress. Maximum fracturing pressures generally will only exceed the minimum in-situ rock stress. Because of the creation of a single (bi-winged) fracture, and the ability to pump large volumes of fluids at (relatively) low rates, the potential penetration for the fracture into the formation can be large, hundreds of feet in many cases.

On the other extreme (Figures 1 and 2(c)), explosive fracturing involves a very rapid loading of the target formation resulting in a highly fractured zone around the wellbore, but usually to a radius not exceeding 10 feet. Because the peak pressures exceed both the minimum and maximum horizontal in-situ stresses, a radial fracture pattern is created, which can be an advantageous fracture geometry where near-wellbore stimulation is the primary objective. Unfortunately, the peak pressures can also exceed the rock yield strength which, when coupled with the high induced compressive stresses in the vicinity of the wellbore, can cause compaction to such a degree that permeability is frequently decreased in the near-wellbore region, resulting in a damaged zone.

Between these two extremes is pulse fracturing, (Figures 1 and 2(b)) which is characterized by peak pressures exceeding both the maximum and minimum in-situ stresses (also creating a radial fracture pattern), but not to a level that exceeds the rock yield strength (hence avoiding the damage associated with the explosive fracturing approach). This technique results

in multiple vertical fractures extending radially from the wellbore, with penetrations on the order of 10 to 20 feet in some cases. This technique captures the radial stimulation attribute of an explosive approach, but without the associated damage. 
Two of these generalized fracturing techniques, in particular hydraulic and pulse fracturing, hold promise for gas storage applications. Accordingly, the five specific technologies that are being considered for this project fall into these categories; three are considered hydraulic in nature (tip screenout, liquid carbon dioxide with proppant, and straight nitrogen without proppant) and two are pulse in nature (propellant and nitrogen pulse). The following sections describe each of these particular techniques in further detail, and their potential application to gas storage wells.

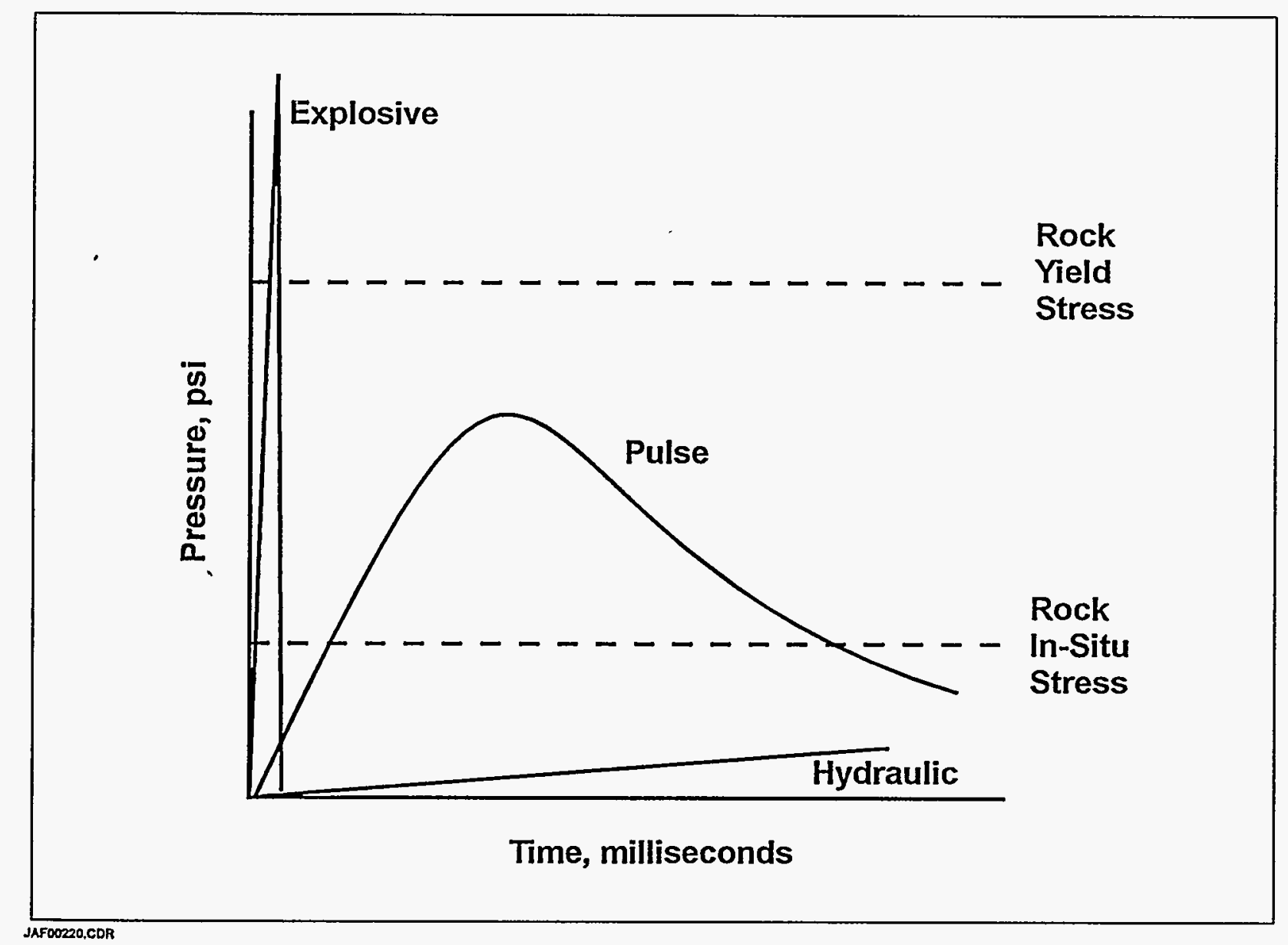

Figure 1

Comparison of Pressure Histories for Rock Fracturing Techniques 


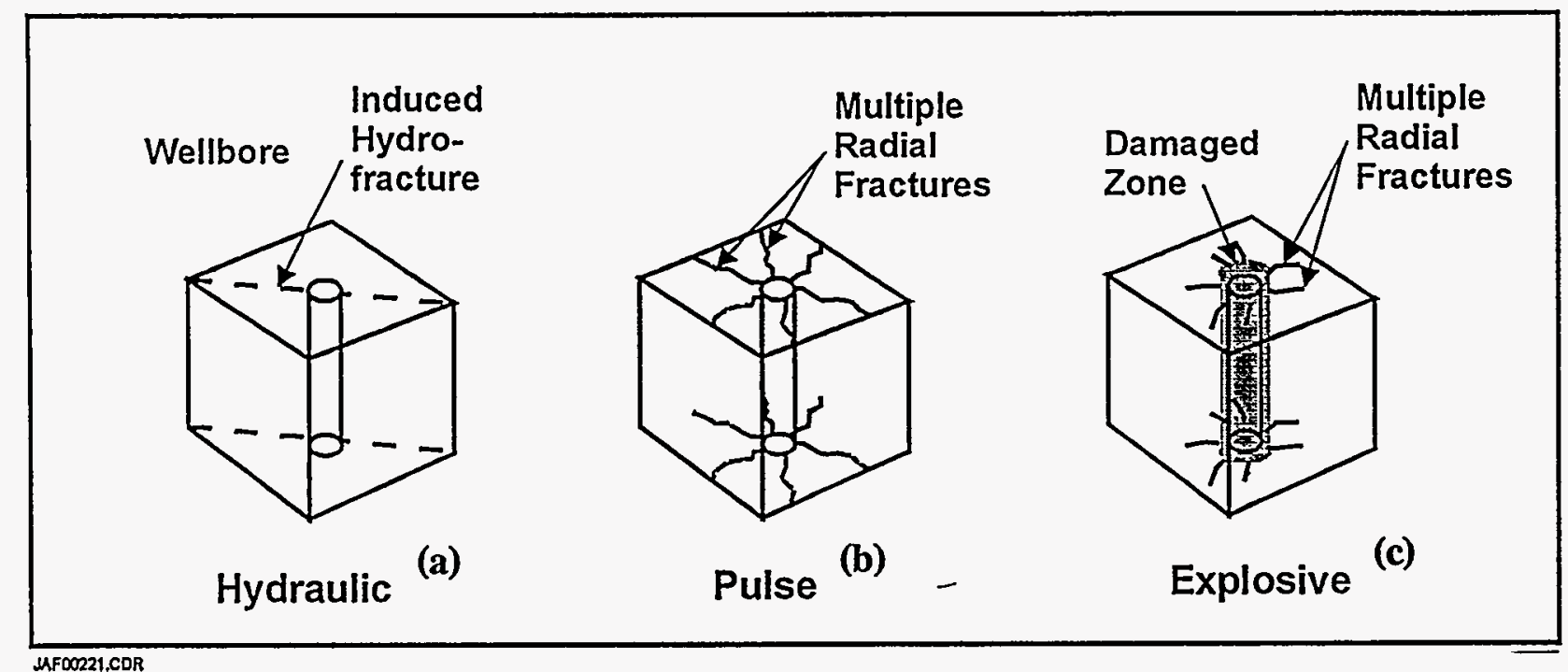

HFDO221.CDR

Figure 2

Comparison of Created Fracture Geometries for Rock Fracturing Techniques

\subsection{Hydraulic Fracturing}

Hydraulic fracturing involves the creation of a single, planar, vertical fracture (except in shallow zones where horizontal fractures can be created) which extends in two wings (180 apart) from a wellbore (Figure 3). The fracture is created by pressurizing the wellbore with a fracturing fluid until the reservoir rock cracks, and then extending that fracture by continued injection of fluid. Fracturing occurs at pressures that slightly exceed the minimum in-situ stress, and is oriented perpendicular to this stress direction. A solid proppant, normally sand, is carried with the fluid such that when injection ceases and the fracture begins to close, it is propped open. This creates a highly conductive flow path for reservoir fluids, in this case storage gas, to be rapidly produced from the reservoir as needed, the proppant serving to maintain the integrity of that flow path.

In the oil and gas community, hydraulic fracturing is utilized to stimulate production from low permeability reservoirs, and as such, deeply penetrating fractures on the range of 200-500 


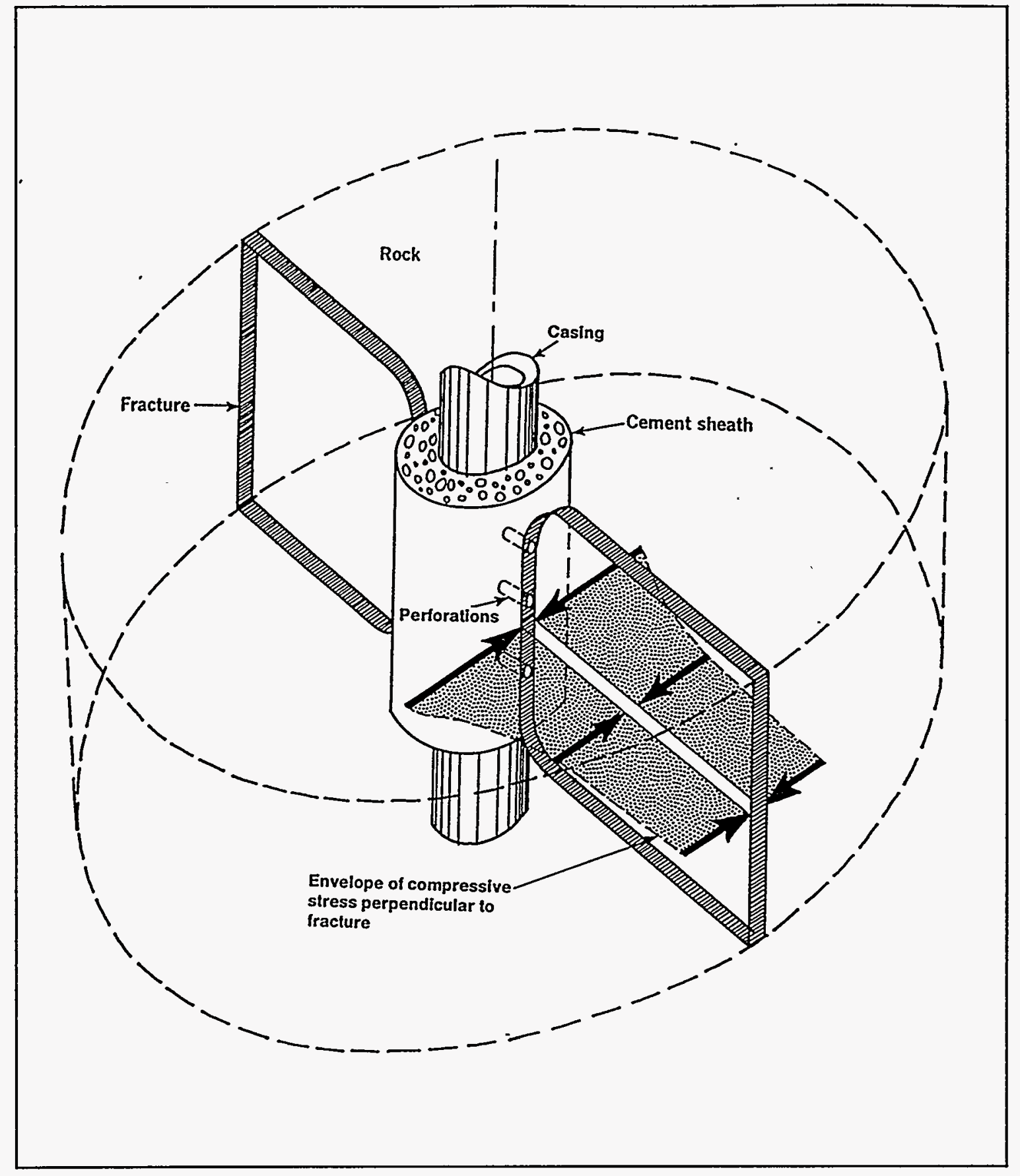

Figure 3

Schematic of a Hydraulic Fracture 
feet per wing are normally required. The needs of the gas storage industry, however, are quite different. Short fractures, probably no more than 100-200 feet in length, will probably be sufficient to penetrate beyond near-wellbore formation damage and enhance well deliverability in these frequently high permeability settings. In addition, because the effectiveness of the fracture is determined by the permeability contrast between the formation and the fracture, and since gas storage reservoirs frequently have reasonably high permeabilities, ultra-high fracture conductivities are required. Ultra-high fracture conductivities are not easily achievable with routine hydraulic fracturing approaches, and therefore less conventional techniques are needed. One such method, proposed for this project for this very reason, is tip screenout fracturing.

\subsubsection{Tip Screenout Fracturing}

\section{Concept}

For high permeability formations, benefits arising from propped hydraulic fractures are directly related to the fracture conductivity (fracture width times fracture permeability), and historically there are only a limited number of ways to increase this value. The first is to increase proppant-pack permeability. Better, stronger proppant types can be used such that a larger proppant size can be used, and, fortunately for depths common to gas storage reservoirs, this can be considered because proppant crushing is usually not a factor. Yet there is still a limit as to how large a proppant grain size can be before proppant bridges in the fracture (or even in the perforation tunnels), causing treatment failure. Thus, beyond a certain point, fracture conductivity cannot be increased via the conventional fracturing approach of utilizing larger proppant grain size.

The alternative is to increase propped fracture width, and again there are only limited alternatives available. While a hydraulic fracture is propagating, its width is related to formation modulus (which is fixed by nature), pump rate and fluid viscosity (but width is only related to these variables to the one-quarter power), and lastly fracture length and/or height. While the use of high viscosity fluids and/or higher pump rates will tend to increase fracture width, very viscous fluids pumped at high rates would only exaggerate the tendency for a fracture to grow 
out of zone, a condition clearly to be avoided in gas storage reservoirs. Thus, it seems that there is limited possibility of increasing width. However, the above relationships between width, pump rate, treatment size, etc. are valid only while a hydraulic fracture is propagating. What if fracture propagation (lateral and vertical fracture growth) were halted by some mechanism, but pumping continued? In such a case, the continued pumping could only serve to increase fracture width.

In order to consider how one might intentionally halt fracture propagation, a normal propped fracture treatment is considered. First, a pad stage is pumped, and this stage of clean, non-proppant laden fluid serves to initiate and open a fracture. This fluid also supplies the sacrificial pad which leaks off into the formation as the fracture grows. Next, proppant-laden stages are pumped which follow the pad into the fracture. As pumping continues, fracture growth continues and the volume of pad is continuously diminished by fluid loss from the fracture into the formation. Eventually, the pad volume is totally depleted. For a conventional design, this point should come just as a treatment is completed. That is, sufficient pad was pumped to create the desired fracture length, and the created fracture was then filled with proppant from the wellbore to the tip.

However, what would happen if pumping continued past this point? Additional fracture growth or extension could not occur since solids would be bridged in the narrow width near the fracture tip, as illustrated in Figure 4. Since lateral/vertical fracture growth would be impossible, any additional pumping would serve to increase fracture width, and the additional proppant placed in the fracture coupled with slurry dehydration would create a highly conductive

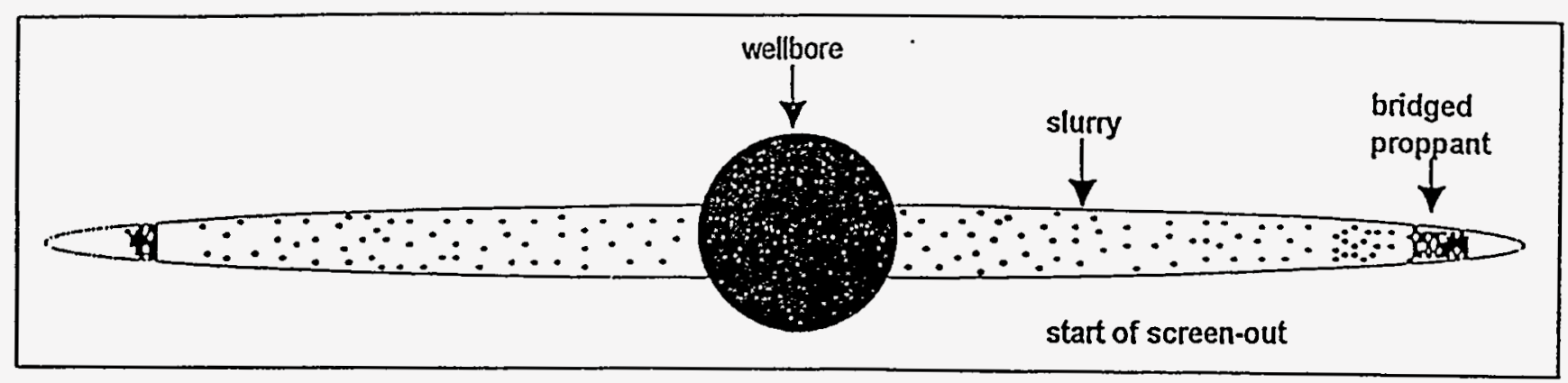

Figure 4

Schematic View of a Tip-Screenout 
pack of proppant that gradually evolves from the tip of the fracture to the wellbore. The sequence of events involved in this process is illustrated in Figure 5. Thus, the pad volume is designed to deplete just as the desired fracture length is created, at which time the proppant reaches the fracture tip, arresting further growth in fracture length. The intentional creation of this behavior, termed tip-screenout fracturing, has led to significant productivity increases from high permeability formations in the North Sea, Alaska, Gulf of Mexico, and other areas, as described below.

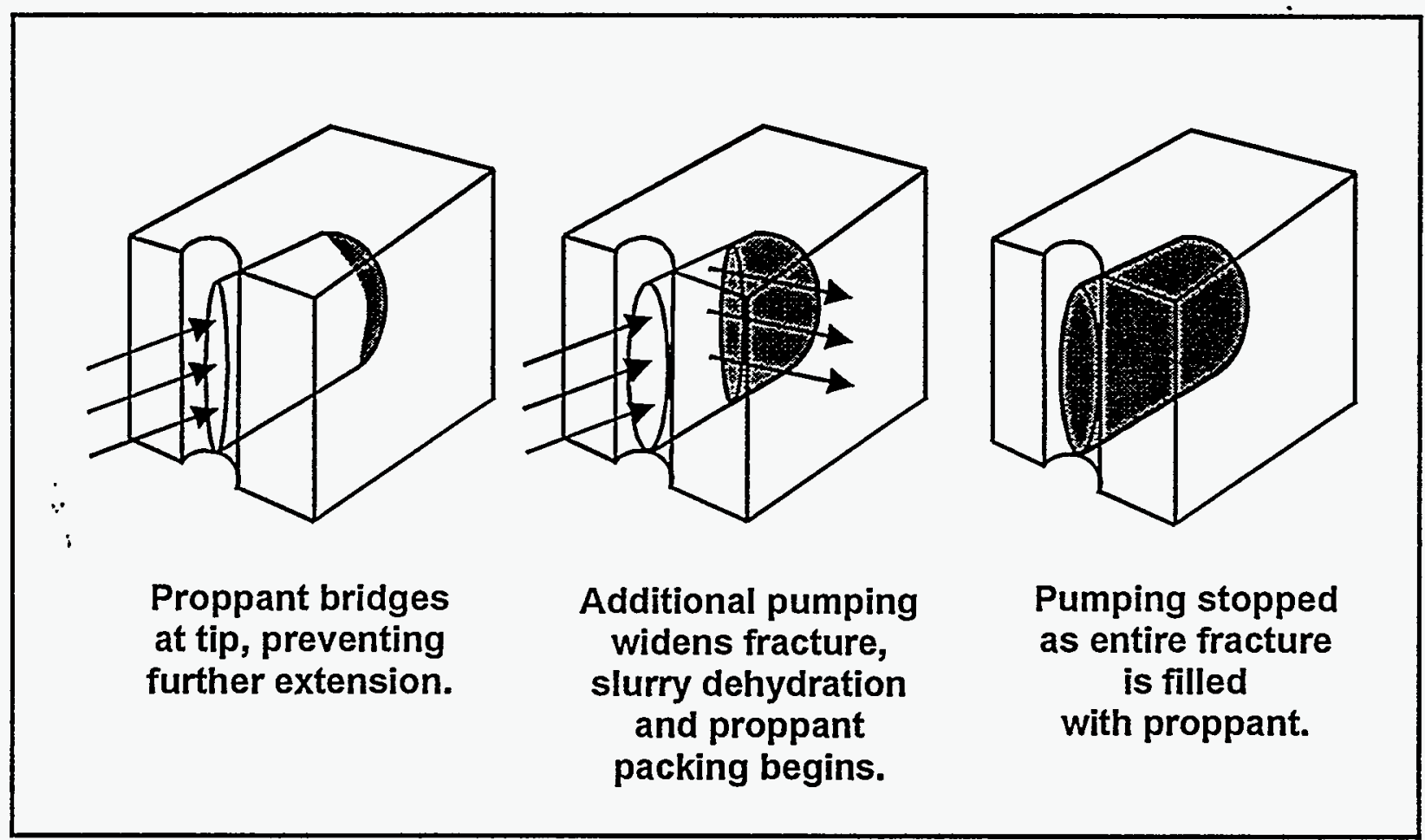

JAF00218,CDR

Figure 5

Sequence of a Tip-screenout Fracture Treatment

\section{History and Current Applications}

Tip-screenout phenomena has been observed since the initial application of hydraulic fracturing in the 1940's, however it was normally viewed as a failure of a conventional treatment (i.e., the pad volume was too small and the well screened-out before the desired proppant volume was pumped). Ken Nolte and Michael Smith first introduced the idea of intentional tip screenout fracturing in their 1981 paper, "Interpretation of Fracturing Pressures. ${ }^{44}$ This paper 
presented the net pressure versus time plot, which pioneered bottom-hole treating pressure analysis for fracturing, and formed the theoretical basis of a tip screenout treatment. The specific concept of designing short, precise hydraulic fractures was further expanded later in $1981^{5}$.

- Consequent to these theoretical developments, during the mid-1980's, the tools required for designing and successfully implementing a tip-screenout treatment became available, namely 3-dimensional predictive and real-time hydraulic fracturing models, and the evolution of minifracturing techniques. Three-dimensional models have the capacity to predict fracture growth behavior in a more accurate fashion than the predecessor 2-D models, and mini-fracturing techniques are used to determine fluid loss behavior of the stimulation fluid in the field prior to the main treatment to further enhance the accuracy of treatment modeling. Accurate fracture modeling is critical for successful tip-screenout treatment design and implementation. In addition, the development of continuous-mix gels during the 1980's also enhanced the ability to successfully implement tip-screenout treatments. These gels, which are created "on-the-fly", provided the flexibility to reduce or extend pumping times until a tip-screenout was achieved and the fracture was fully packed with proppant. This eliminated the expense of pre-mixing large volumes of gelled fluid which would be wasted if not used. These developments put all of the elements into place for designing and implementing precise hydraulic stimulation treatments at a reasonable cost, a fundamental requirement for successful tip-screenout fracturing.

The first published application of an intentional tip screen-out fracture treatment was in 1984 as a means of maintaining proppant bed conductivity in a soft, unstable Upper Cretaceous chalk formation in Amoco's Valhal Field in the North Sea, ${ }^{6,7}$ Although the formation permeability was not high (1-2 md), wide, highly conductive fractures were required to mitigate fracture conductivity reduction as a result of proppant embedment and plugging with formation fines. Amoco found that where tip-screenout treatments were performed, higher producing rates could be achieved at lower pressure drawdowns, and sand and formation solids were not produced to the surface as was typical after a conventional treatment. Shortly thereafter, BP Petroleum Development also began utilizing tip-screenout treatments in the Ravensprun Field 
of the UK Sector of the North Sea. They, too, reported successful treatment results, with production increases up to sevenfold.

While the utilization of tip-screenout fracturing continued in the North Sea, its application expanded to Alaska's Prudhoe Bay. Here, the objective was to place short, highly conductive fractures into a high permeability oil-bearing section without fracturing into the underlying aquifer; this has traditionally been accomplished with a small, conventional treatment ${ }^{8}$. Since 1989, however, BP and Arco Alaska have been utilizing tip-screenout fracturing and report considerable success; the technique continues to be routinely applied there. Following this, tipscreenout fracturing started being employed as a damage-removal method in high permeability formations of Indonesia'. It was here that tip-screenout fracturing was first utilized in conjunction with a gravel-pack completion.

Today, tip-screenout treatments are perhaps most notably known as the "frac and pack" technique popular in the Gulf of Mexico ${ }^{10,11,12,13}$. Similar to the approach in Indonesia, the treatment serves as both a well stimulation and formation consolidation technique; the highly permeable, unconsolidated nature of the sand reservoirs in the Gulf of Mexico has historically required the use of gravel packs to prevent solids production. Unfortunately these completions frequently result in formation damage. The "frac and pack" technique creates a short, highly conductive hydraulic fracture and, by pumping sand consolidation material during the latter stages of the treatment, also consolidates the completion, minimizing solids production. Similar dual-purpose treatments have now also been performed in Australia and West Africa ${ }^{14,15}$.

\section{Application To Gas Storage}

Tip-screenout fracturing technology holds considerable potential for revitalizing the performance of gas storage wells for a number of reasons. Firstly, many gas storage reservoirs are characterized by high formation permeability, and in order to achieve a high permeability contrast between the fracture and the formation, which is necessary for a fracture to be effective, a less conventional technology such as tip-screenout fracturing must be employed. 
Secondly, a wide, highly conductive fracture is less-susceptible to damage than a thinner, less conductive fracture. Lower pressure drops during peak withdrawal periods will minimize formation fines mobilization and fracture conductivity reduction. Retained fracture conductivity after the introduction of particulates during injection will also remain relatively high.

Finally, due to the relatively small size of a tip-screenout treatment, and the fact that fracture growth is intentionally restricted, the opportunity for upward and downward fracture penetration of the sealing horizons is minimized. These three attributes of tip-screenout fracturing have each been field-proven based on industry's experience with this technology.

There is, however, a potential difficulty with tip screen-out fracturing when considering its application to gas storage wells. It requires the use of gelled (water-based) fluids to carry the solid proppant, which can create fluid damage around the fracture reducing relative permeability to gas and increasing treatment cleanup times. In addition, gel residue may partially block some pore spaces of the fracture. Some storage operators have, in fact, reported fracture cleanup times as long as several years, even when using nitrogen foam stimulation fluids, which are traditionally viewed as being low-damage systems. This consideration points to a need to also investigate other hydraulic fracturing approaches as part of this DOE/METC RD\&D project. 


\subsubsection{Fracturing with Liquid Carbon Dioxide With Proppant}

\section{Concept}

As mentioned earlier, the principal disadvantage of a water-based fracturing fluid is that it has the potential to create substantial damage to the target reservoir. Formation damage can take a variety of forms for gas well applications, including a reduction in the relative permeability to gas, gel and chemical residue blocking the pore spaces of the reservoir and/or proppant pack, or water-induced swelling of formation clays. These issues have received considerable attention from the gas production industry in recent years, and methods to reduce or eliminate these problems has been the topic of considerable research. One approach to avoid formation damage altogether, and which has a long track record in Canada, is fracturing with liquid carbon dioxide.

The principal benefits of utilizing liquid carbon dioxide as a fracturing fluid are the elimination of unfavorable relative permeability effects, the non-existence of gel and other chemical residues, and the elimination of water induced clay swelling. These complications are eliminated because liquid carbon dioxide is a non-aqueous, non-damaging fluid. In addition, the expansive properties of carbon dioxide may result in effective fluid leakoff control in some instances. These benefits make liquid carbon dioxide fracturing a technique with considerable potential for stimulating gas storage wells.

Fracturing with liquid carbon dioxide is essentially identical to hydraulic fracturing with other low viscosity fluid such as an ungelled water. The carbon dioxide is pumped as a liquid and carries proppant, typically sand, down the wellbore and along the fracture until it settles out. Proppant transport, typical for a low viscosity fluid, is characterized by flushing and proppant banking (i.e., proppant quickly settles out of the treating fluid once it enters the fracture, and is then flushed down the fracture length by the fluid velocity). At the conclusion of the treatment, the well is flowed back and the carbon dioxide is returned to the surface in the gaseous phase. No residual liquids or chemicals are left in the fracture or in the formation. 
The principal difference between fracturing with liquid carbon dioxide and other fluid systems is in the blending requirements. Proppants and carbon dioxide must be mixed in a purpose-built pressurized blending system (Figure 6), of which only three exist today (two of which are in North America and one is in Europe). Because of the need to mix the liquid carbon dioxide and proppant under pressurized conditions, proppant must also be stored and transferred to the blending tub under pressure. As such the blender, shown in Figure 6, is configured to store and deliver the proppant under the required conditions. This places a practical limit on the amount of proppant that can be used with this system, which is based on the capacity of the pressurized proppant storage bin on the blender (about 40,000 lbs). For gas storage applications, however, where only short fractures and required, this is not viewed as a serious limitation.

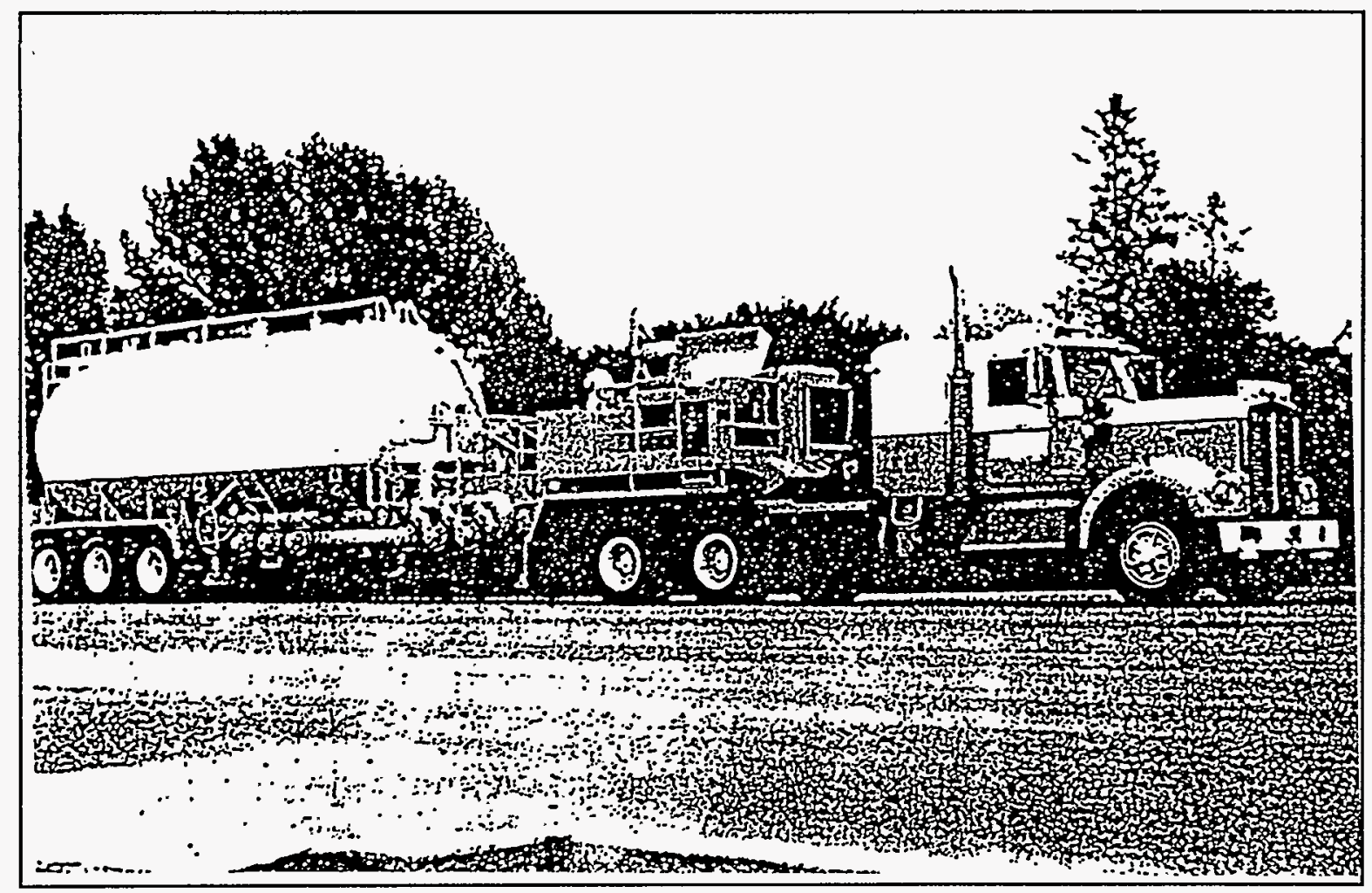

Figure 6

Liquid Carbon Dioxide Blender

A typical liquid carbon dioxide with proppant fracture treatment will consist of 1) wellbore pressurization with nitrogen, 2) a carbon dioxide pad, 3) the carbon dioxide sand-laden stages, and 4) a nitrogen flush. The wellbore is initially loaded and pressurized with nitrogen 
to prevent the generation of dry ice plugs as a consequence of sudden pressure drops when liquid carbon dioxide pumping initiates. To pump the liquid carbon dioxide, it is transferred from the transports to the blender in a liquid form via pressure (no pumping is required for this). Once the liquid carbon dioxide and proppant have been blended, the blender then transfers the liquid carbon dioxide and proppant slurry to conventional high pressure fracturing units for injection into the well. Figure 7 presents a typical carbon dioxide stimulation equipment layout. Note that nitrogen is used to maintain pressure on the carbon dioxide transports to keep it in the liquid phase as they are depleted. A nitrogen flush at the conclusion of the treatment is used to prevent overflushing associated with liquid-to-gas expansion in the wellbore as the temperature of the carbon dioxide increases.

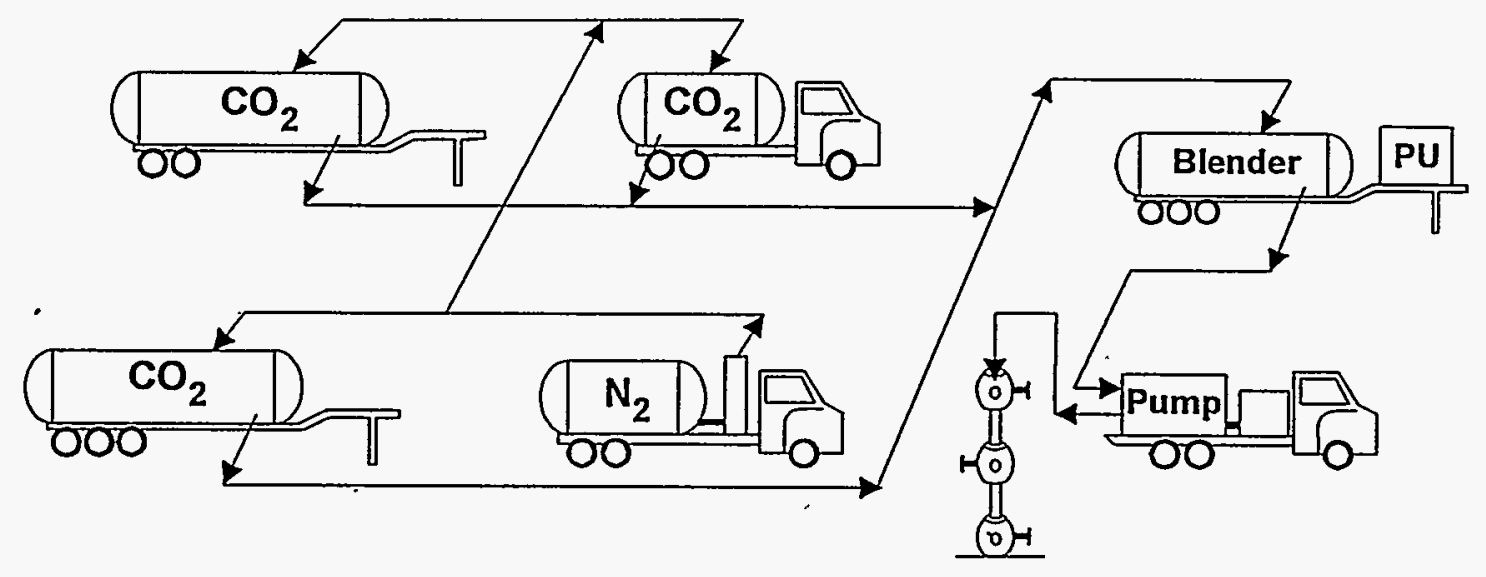

JAF00219.CDR

Figure 7

Liquid Carbon Dioxide Stimulation Equipment Layout

On an interesting side-note, during the early 1980's, hydrocarbon based gelling agents were used to increase carbon dioxide viscosity up to $2 \mathrm{cp}$ and improve proppant placement capabilities. Difficulties in maintaining gel quality and consistency, and limited treatment success, led to discontinuing attempts to gel carbon dioxide. It was further felt the introduction 
of gels into the system undermined the principal benefit of liquid carbon dioxide; namely being a damageless fluid system.

\section{History and Current Applications}

- Liquid carbon dioxide was first used in the 1960's for oil and gas well hydraulic fracturing, however at that time it was primarily utilized as an aid for treatment fluid recovery ${ }^{16}$. Pure carbon dioxide and sand fracturing was first introduced in $1981^{17}$, where it was used to stimulate a Glauconite sandstone well in Canada. This and subsequent treatments were highly successful, providing one-and-a-half fold increases in production over wells fractured with conventional fracturing fluids, and formed the basis for widespread application of this technology in water-sensitive formations throughout Canada. By 1987, it was estimated that over 450 liquid carbon dioxide treatments had been performed. Probably due to the limited availability of suitable blenders to implement these treatments, they have not been widely employed in the United States. Table 1 provides a selected list of the formations in Canada, and a few in the U.S., where this technology has been applied (through 1987); over $95 \%$ of all treatments have been in gas wells ${ }^{18}$.

Table 1

Formations Fractured with Liquid Carbon Dioxide (through 1987)

\begin{tabular}{|c|l|c|c|c||}
\cline { 2 - 5 } \multicolumn{1}{c|}{} & Formation & Depth & $\begin{array}{c}\text { No. } \\
\text { Treatments }\end{array}$ & $\begin{array}{c}\text { Average } \\
\text { Proppant Placed }\end{array}$ \\
\hline \hline \multirow{4}{*}{$\begin{array}{c}\text { United } \\
\text { States }\end{array}$} & Pictured Cliffs & $2310 \mathrm{ft}$ & unknown & $58,000 \mathrm{lbs}$ \\
\cline { 2 - 5 } & Booch & $2708 \mathrm{ft}$ & unknown & $22,000 \mathrm{lbs}$ \\
\cline { 2 - 5 } & Codell & $7314 \mathrm{ft}$ & unknown & $75,000 \mathrm{lbs}$ \\
\cline { 2 - 5 } & Cleveland & $7804 \mathrm{ft}$ & unknown & $75,000 \mathrm{lbs}$ \\
\cline { 2 - 5 } & Red Fork & $13366 \mathrm{ft}$ & unknown & $68,000 \mathrm{lbs}$ \\
\hline \hline \multirow{5}{*}{ Canada } & Basal Quartz & $6024 \mathrm{ft}$ & 49 & $21,000 \mathrm{lbs}$ \\
\cline { 2 - 5 } & Bearpaw & $1007 \mathrm{ft}$ & 85 & $28,000 \mathrm{lbs}$ \\
\cline { 2 - 5 } & Belly River & $1772 \mathrm{ft}$ & 96 & $30,000 \mathrm{lbs}$ \\
\cline { 2 - 5 } & Cardium & $6768 \mathrm{ft}$ & 16 & $36,000 \mathrm{lbs}$ \\
\cline { 2 - 5 } & Glauconite & $4495 \mathrm{ft}$ & 59 & $23,000 \mathrm{lbs}$ \\
\cline { 2 - 5 } & Viking & $3963 \mathrm{ft}$ & 45 & $20,000 \mathrm{lbs}$ \\
\hline \hline
\end{tabular}


DOE/METC has been instrumental in recent years in demonstrating the application and benefits of this approach to water-sensitive gas reservoirs in the United States ${ }^{19}$. In a recent field case history in the Appalachian Basin, liquid carbon dioxide fracturing was found to substantially outperform the traditional nitrogen-foam approach in wells completed in the Berea sandstone ${ }^{20}$. A total of fifteen wells in Pike and Martin Counties, Kentucky, were fractured using different fluids, being either the traditional nitrogen foam approach, straight nitrogen (without proppant) or liquid carbon dioxide (Figure 8). After nine months of production, the wells fractured with liquid carbon dioxide had produced twice the volume of gas as those fractured with straight nitrogen, and five times the volume of gas as those fractured with nitrogen foam (Table 2). Currently, DOE/METC is preparing to also demonstrate the application of this technology in the water-sensitive tight-sand formations of the Rocky Mountain region.

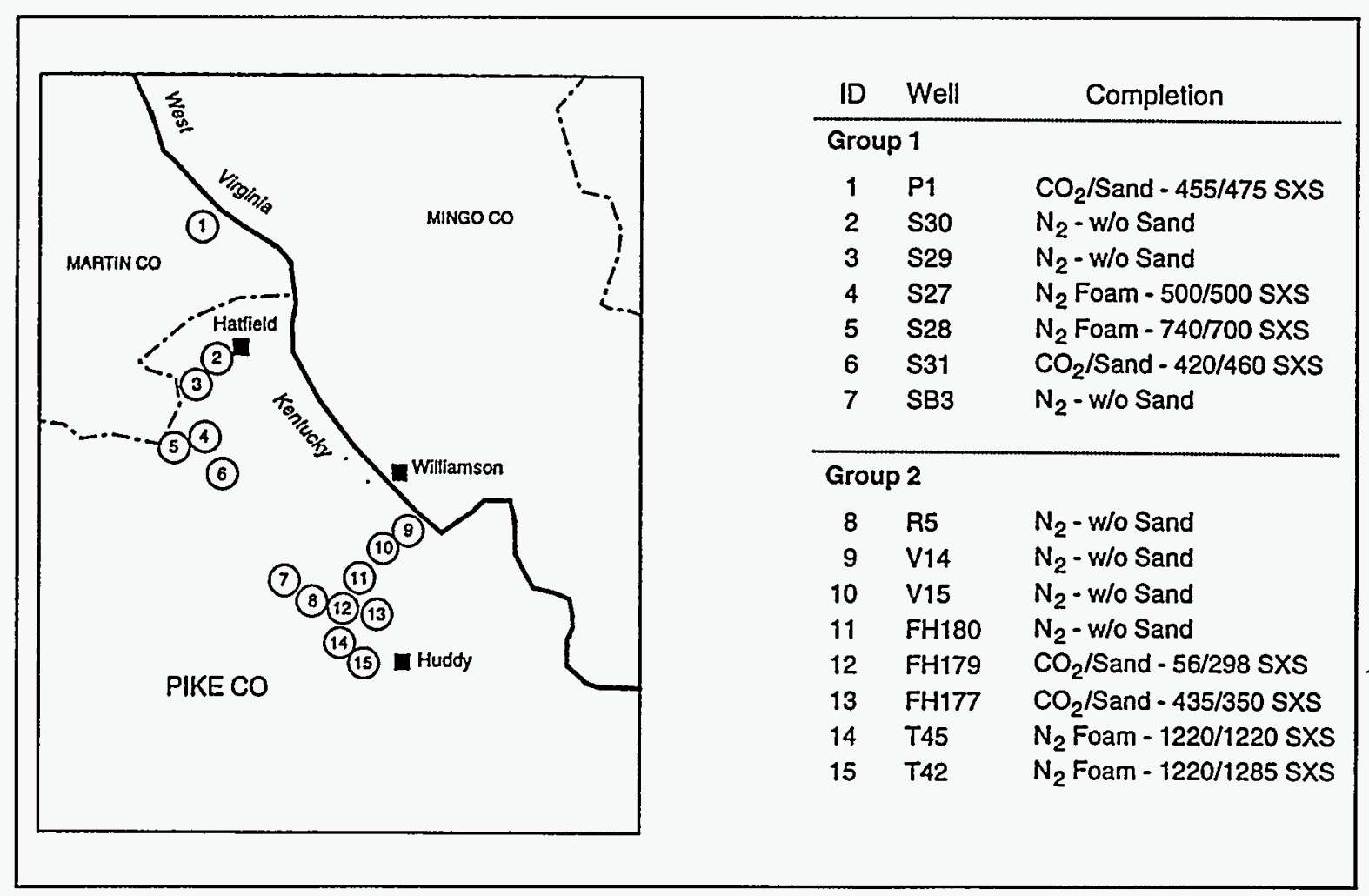

Figure 8

Liquid Carbon Dioxide Fracturing Study Area 
Table 2

Production Results from Liquid Carbon Dioxide Fracturing Case Study

\begin{tabular}{||l|c|c|c||}
\hline \multicolumn{1}{|c|}{ Group } & 1 & 2 & $\begin{array}{c}\text { Combined Average } \\
\text { (MMcf per Well) }\end{array}$ \\
\hline \hline CO2/Sand & $41.5 \mathrm{MMcf}$ & $14.3 \mathrm{MMcf}$ & 27.9 \\
\hline N2 Gas & $19.2 \mathrm{MMcf}$ & $10.8 \mathrm{MMcf}$ & 14.4 \\
\hline N2 Foam & $6.1 \mathrm{MMcf}$ & $5.4 \mathrm{MMcf}$ & 5.7 \\
\hline \hline \multicolumn{1}{|c|}{ Group } & Benefit Ratio & Incremental Gas (MMcf) \\
\hline \hline CO2/Sand : N2 Gas & 1.9 & \multicolumn{2}{|c|}{13.5} \\
\hline $\begin{array}{l}\text { CO2/Sand : N2 } \\
\text { Foam }\end{array}$ & 4.9 & \multicolumn{2}{|c}{22.2} \\
\hline
\end{tabular}

\section{Application to Gas Storage}

The principal benefit of liquid carbon dioxide fracturing for gas storage reservoirs is identical to that for gas production wells -- the elimination of formation damage and rapid cleanup. This may be particularly significant since many storage operators have reported that it will frequently take a year or more for a well that has been fracture-stimulated to clean-up and begin showing signs of improvement. By providing a more immediate benefit, liquid carbon dioxide may be of particular value for gas storage wells.

The principal disadvantages of liquid carbon dioxide fracturing are the limited proppant volumes pumpable, low fluid viscosity, and equipment availability. As described earlier, proppant is stored in a pressurized vessel (blender) during the treatment, which can currently contain only a limited amount of proppant and cannot be restocked during the treatment. This limits the size of treatments using this system. However, for the size of treatments envisioned for gas storage wells, this is not anticipated to be a problem.

Since liquid carbon dioxide has a low viscosity, proppant transport is similar to that when utilizing ungelled water, only with poorer transport capabilities. In addition, the low fluid 
viscosity results in a limited fracture width, and hence a reduced fracture conductivity. However, in formations where tip screenout is not applicable or where water damage is a major concern, $\mathrm{CO}_{2}$ sand fracs may provide superior deliverability results. Finally, the principal equipment component, the blender, are few in number (3). Two of these are located in North America however.

\subsubsection{Fracturing with Nitrogen}

\section{Concept}

As implied in the previously cited DOE/METC fracturing RD\&D project in Kentucky, fracturing with gaseous nitrogen is also a viable stimulation technique for formations sensitive to aqueous-based fracture fluid systems. In this case, nitrogen is pumped as a cryogenic liquid and then heated to form a gas prior to being injected into the well. Fracturing mechanics occur as in any other hydraulic fracturing technique, the only difference being that the fracturing fluid is a gas. Unfortunately, pumping nitrogen as a gas normally eliminates the possibility of transporting proppants, and as such, nitrogen fracturing can be classified as a proppantless, nonreactive stimulation technique.

Proppantless stimulation techniques depend on self generating propping mechanisms; shear displacement between fracture faces may result in conductive self propping channels, and block sliding and dilation of joints may also create high permeability paths in naturally fractured reservoirs. Typically, however, production improvements using proppantless fracturing techniques are relatively short-lived as the induced fractures close and heal over time. However, proppantless stimulations are implemented at minimal fracturing rates, and thus reduce the potential for fracturing out-of-zone.

\section{History and Current Applications}

Proppantless hydraulic fracturing has been practiced as a means of well stimulation since the concept of hydraulic fracturing was first developed. Typically, however, reservoir fluids or 
water was utilized. Two particular cases, namely British Petroleum's experience with proppantless crude oil fracturing in the Egmanton and Bothamsall oil fields in central England in the mid-late 1950 ' $\mathrm{s}^{21}$, and similarly by others in the Los Angeles Basin in the 1960 ' $\mathrm{s}^{22}$, demonstrated the potential of proppantless fracturing techniques to achieve short-term productivity gains. Later, in the late 1970's, low-rate proppantless nitrogen foam treatments were. successfully employed by coalbed methane researchers in the Black Warrior Basin to confine hydraulic fracture heights to the zone of interest ${ }^{23,24}$.

Beginning at about this same time, and continuing today, proppantless nitrogen fracturing began gaining popularity as a stimulation technique for the water-sensitive formations of the Appalachian Basin. In a case study of five Ohio Shale wells fractured using proppantless nitrogen, the method was reported to be "successful", but fairly rapid early production declines were observed as the created fractures began to heal ${ }^{25,26}$. The technique was also applied with similar results in the Atoka Formation of the Fort Worth Basin. Most recently, DOE/METC investigated the application of this technology in a field RD\&D program in the Pike County area of the Appalachian Basin. Those results, presented earlier, indicated that at least in the shortterm, straight nitrogen treatments can outperform the traditionally utilized nitrogen foam treatments in that area.

Finally, in an interesting new development of this technology, sand proppant has been added to a gaseous nitrogen fracturing treatment ${ }^{27}$. In 1983, a total of 17 such treatments were publicly reported, almost exclusively performed in the Devonian shale formations of Ohio and West Virginia. Effective treatment rates ranged from 10 to 92 barrels/minute with up to 5400 pounds of 20/40 proppant being placed. In one particular case, the Goose Creek field in Ritchie County, West Virginia, a nitrogen gas with sand treatment was directly compared to a nitrogenonly treatment. The post-stimulation production results, shown in Figure 9, indicate that the nitrogen treatments where proppant was utilized substantially outperform those where it was not. This approach may be worthwhile considering for gas storage applications. 


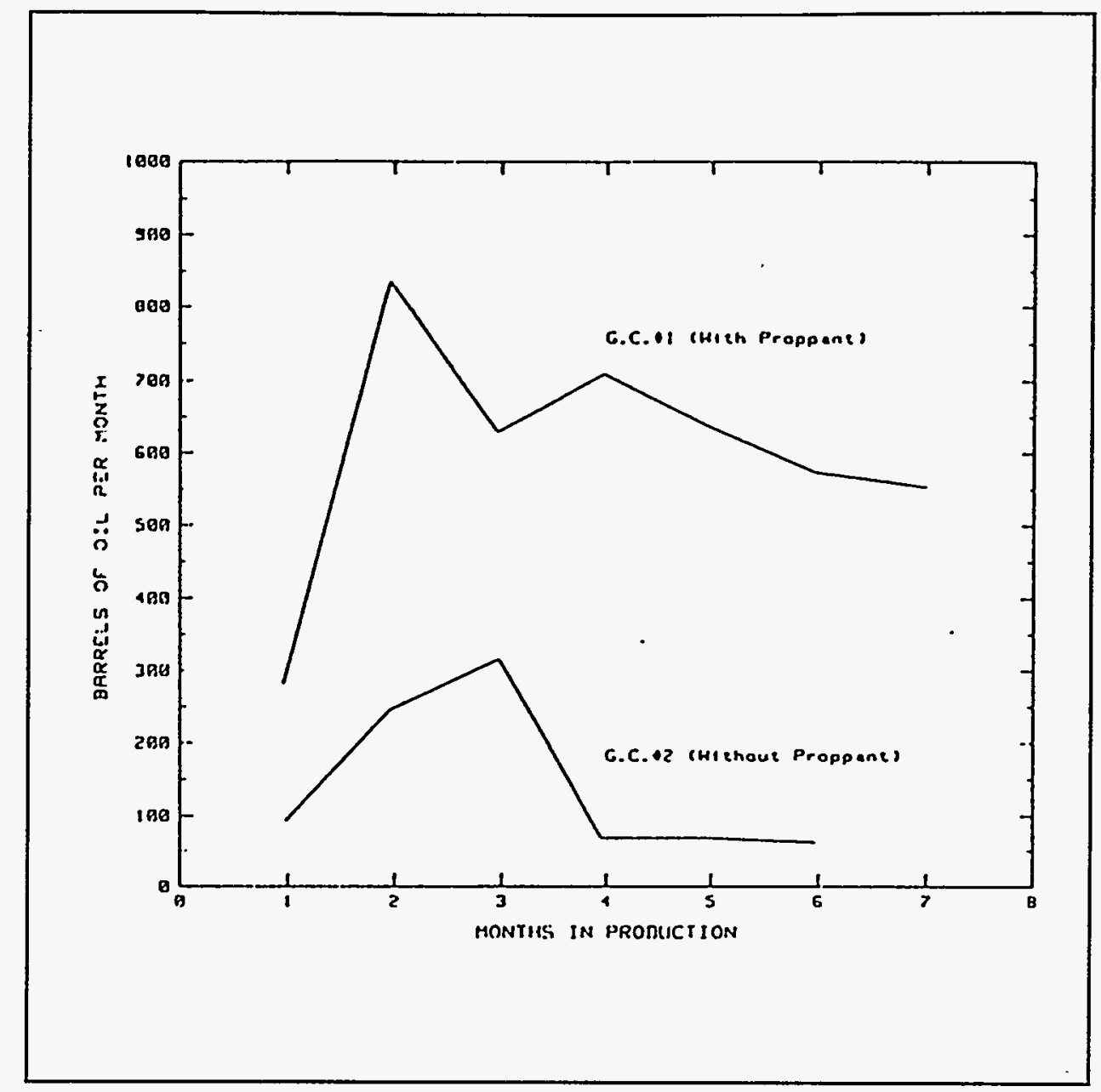

Figure 9

Comparison of Production Results When Fracturing with Nitrogen

\section{Application to Gas Storage}

As with fracturing with liquid carbon dioxide, the principal benefit of fracturing with gaseous nitrogen is the non-aqueous, non-damaging nature of it, particularly in water sensitive formations. Many gas storage operators have indicated that fracturing cleanup times can be very long, several years in some cases, and it is in these environments that nitrogen fracturing may be of greatest benefit.

It is uncertain to what degree an unpropped fracture created with nitrogen may retain its conductivity in a gas storage reservoir. The high flow rates and associated fines mobilization 
and scale deposition my accelerate the plugging of a thin, unpropped fracture. The extreme ranges and rapid changes in net fracture closure pressures that occur during the course of a full injection/withdrawal cycle may further promote the fracture healing process. Therefore, the use of proppant with a gaseous nitrogen treatment may be required in gas storage applications.

\subsection{Pulse Fracturing}

Because of the relatively short fracture lengths required to overcome near-wellbore damage in gas storage wells, other fracturing techniques outside of hydraulic fracturing also hold potential for deliverability enhancement. Pulse fracturing in particular deserves investigation as part of this DOE/METC RD\&D project. As described earlier, the primary difference between pulse fracturing and hydraulic fracturing is the rate at which energy is applied to the formation to create fractures. In hydraulic fracturing, this rate is relatively low and results in the extension of a single, relatively long fracture which propagates perpendicular to the least principal in-situ stress. Pulse fracturing involves much more rapid energy discharge creating a series of vertical fractures, each perhaps 5 to 20 feet in length, propagating radially outward from the wellbore. Figure 10 presents a typical schematic of pulse fracturing results. One pulse fracturing technique that has been successfully applied in a variety of damage-removal type applications is propellent gas fracturing.

\subsubsection{Propellent Fracturing}

\section{Concept}

Propellant fracturing, also known as controlled pulse fracturing, tailored pulse loading or high energy gas fracturing, involves the use of a wireline run, electrically ignited propellant (similar to solid rocket fuel) which is placed across the formation to create a high pressure pulse. This pulse of gas creates multiple short $(5-20 \mathrm{ft}$ ) radial fractures in the formation which connect to the wellbore and are confined close to the zone stimulated. The propellants in a typical tool burn to form mainly carbon monoxide and some water, but the amounts are small so that fracturing occurs without much damaging fluid contact. In addition, the small gas 


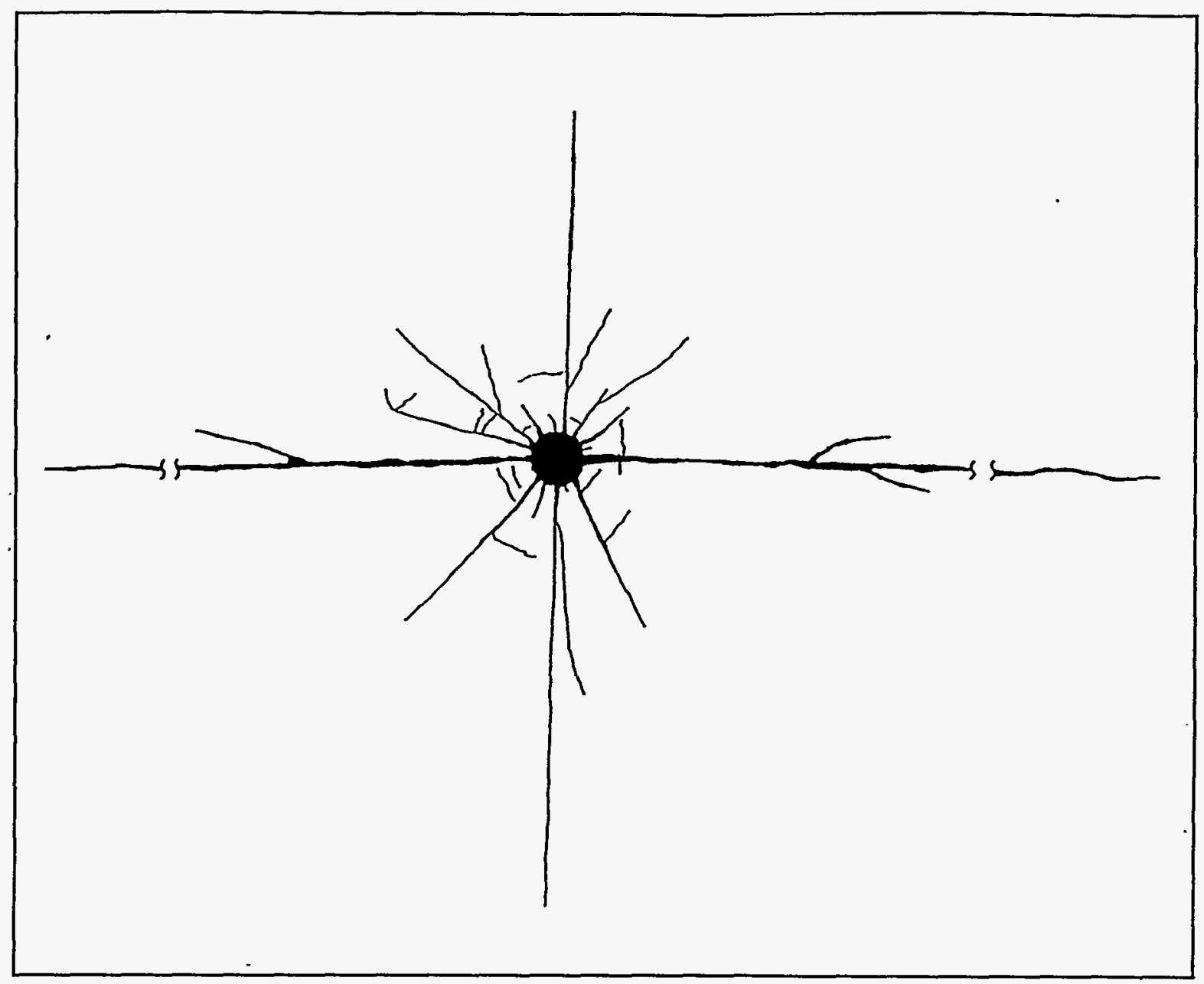

Figure 10

Conceptual Model of Pulse Fracturing Results

volume limits the extent of fracturing both radially and vertically.

Propellant fracturing is designed to increase the pressure in the wellbore above the in-situ and tensile rock stresses to create the multiple fractures, but still remain below the yield stress of the rock, thus avoiding the wellbore damage associated with explosive fracturing. The fracturing process consists of three stages ${ }^{28}$. These are shown conceptually in Figure 11 and described below. 


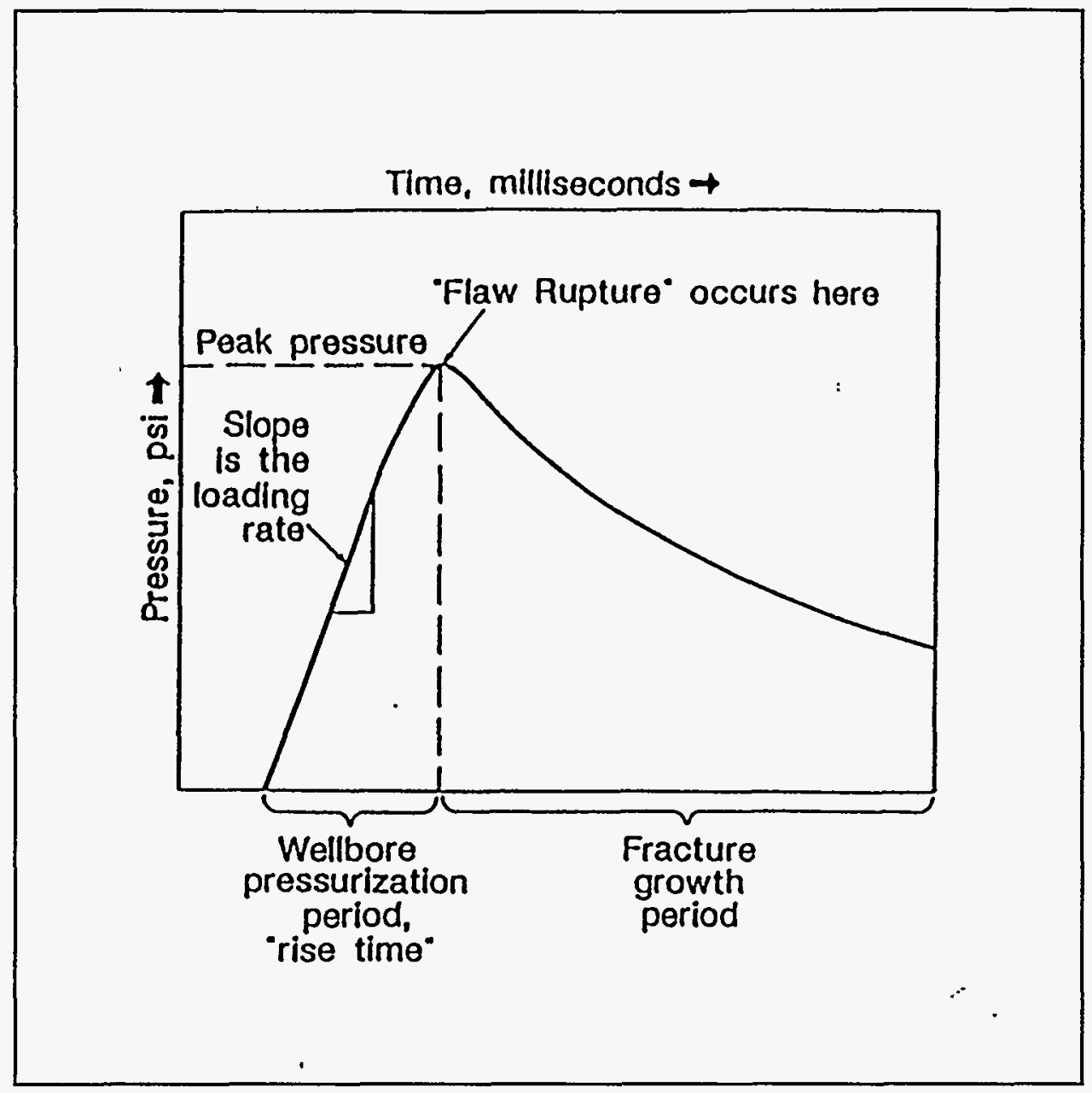

Figure 11

Idealized Pressure History for Propellant Fracturing

During wellbore pressurization (first stage), the wellbore elastically deforms and natural flaws in the formation pressurize. The gas generated from the propellant simply acts as if it were in a closed chamber. This stage is generally seen as a linear increase in pressure with time. The "loading rate" is defined as the peak pressure divided by the time to achieve it (i.e., the "rise time"), and can typically be in the range of 5,000-15,000 psi per millisecond. The loading rate is the most important variable in achieving multiple fracturing, as too high a loading rate causes formation damage and to low a loading rate only creates fractures in the preferred hydraulic fracture direction. 
The second (flaw rupture) stage is not well understood. In any wellbore there will become distribution of flaws either from intersected natural fractures or from some other inhomogeneity in the formation. The flaw rupture could be from gas pressurization or from stress related failure. However, it appears that the exact nature of the flaw rupture may not be important except that enough flaws must exist to provide fracture paths. In cased and perforated wells the flaws are provided by the perforation tunnels.

The efficiency of fracture extension (stage 3) is critical in providing the lengths of fractures necessary to connect the wellbore past formation damage and to provide the highest level of stimulation. It is generally accepted that the fractures are extended by the outward flow of high energy gas created in the wellbore. Fracturing ceases when the wellbore pressure dissipates to below the minimum in-situ stress. The fracture growth period is hence somewhat controllable in as much as additional proppellant can be utilized to generate greater volumes of high energy gas.

\section{History and Current Applications}

Early field scale tests of propellant fracturing were performed by Sandia Laboratories at DOE's Nevada Test Site in the late 1970 ' $\mathrm{s}^{29}$. The tests were run in open holes drilled into the tunnel walls in the G Tunnel Complex underneath Rainer Mesa. The test holes were then mined out to determine the extent of fracturing. The first tests proved multiple fractures could be generated in real rock if the pressure loading rate is between that of hydraulic fracturing and that of explosive fracturing, and that the fracture region was contained within the six feet of the zone treated. Additional tests at the site compared several propellant and explosive techniques and furthered the development of tool construction ${ }^{30}$.

Following the tests in the tunnel complex, design criteria and hardware were sufficiently developed to perform several stimulation experiments in producing wells. Experiments were conducted in two Devonian shale wells, one in Rowan County, Kentucky and the other in Meigs County, Kentucky ${ }^{31}$. In the first experiment, designed to demonstrate that the observations from the ash-fall tuff of the Nevada Test Site could be replicated in shales, two propellent treatments 
were performed, the first in the Lower Huron formation and the second in the Middle Huron formation. Post-treatment borehole television logs verified that the technology developed at the Nevada Test Site was equally valid in the Devonian Shales of the Appalachian Basin.

The second well, located in a site of considerable prior field RD\&D work on fracturing, was also stimulated in the Lower Huron formation. The measured pre- and post-stimulation skin factors for this well, compared to similar test data from two nearby wells stimulated using both an explosive and hydraulic fracturing approach, are provided in Table 3. This information suggests that propellant fracturing can be an effective stimulation method in shale wells.

Table 3

Stimulation Results for the Meigs County Site

\begin{tabular}{|c|c|c|c||}
\hline \multirow{2}{*}{ Well } & \multirow{2}{*}{ Treatment } & \multicolumn{2}{|c|}{ Skin } \\
\cline { 3 - 4 } & & Before & After \\
\hline \hline 10056 & Explosive & n.m. & -3 \\
\hline $10056 \mathrm{~B}$ & Propellant & +12 & -2 \\
\hline $10056 \mathrm{C}$ & $\begin{array}{c}\text { Nitrogen } \\
\text { Foam Frac }\end{array}$ & +19 & -3 \\
\hline
\end{tabular}

At about this same time, in the early-mid 1980's, Diamond Shamrock tested the propellant fracturing method in the Upper Cretaceous Ferguson sandstone formation in Campbell County, Wyoming ${ }^{32}$. A total of seven oil wells were treated in the Empire and Ibelin Fields. Propellant fracturing was utilized because of the sensitivity of the formation clays to other stimulation fluids, such as acids and hydraulic fracturing fluid systems, and because propellant fracturing was perceived to possess little potential for fracture height growth; the Ferguson was underlain by the wet Upper Parkman formation, and the two horizons were separated only by a 2 to 8 foot shale stringer. The results of the stimulation treatments, specifically the pre- and post-treatment flow rates, are provided in Table 4 . The oil production rate in each case was improved, albeit only slightly in some cases. Importantly, however, is that there was no evidence that the treatments broke through the underlying shale barrier, suggesting fracture height growth is limited in these treatments. 
Table 4

Pre- and Post-Stimulation Production at the Empire and Ibelin Fields

\begin{tabular}{|c|c|c|c|c||}
\hline \multirow{2}{*}{ Well } & \multicolumn{2}{|c|}{ Pre-Treatment } & \multicolumn{2}{c|}{ Post-Treatment } \\
\cline { 2 - 5 } & $\begin{array}{c}\text { Oil } \\
\text { (Bpd) }\end{array}$ & $\begin{array}{c}\text { Water } \\
\text { (Bpd) }\end{array}$ & $\begin{array}{c}\text { Oil } \\
\text { (Bpd) }\end{array}$ & $\begin{array}{c}\text { Water } \\
\text { (Bpd) }\end{array}$ \\
\hline \hline 1 & 3 & 0 & 9 & 0 \\
\hline 2 & 3 & 0 & 8 & 0 \\
\hline 3 & 39 & 0 & 42 & 0 \\
\hline 4 & - & - & 5 & 15 \\
\hline 5 & 3 & 0 & 8 & 0 \\
\hline 6 & 15 & 0 & 25 & 0 \\
\hline 7 & 2 & 1 & 3 & 1 \\
\hline
\end{tabular}

Recently, testing of propellant fracturing has been extended to cased and perforated wellbores. These tests were also performed in the G-tunnel complex in Nevada. An example of the fracture patterns obtained in a specific cased and perforated well is shown in Figure 12. The figure shows the fracture patterns starting in the perforation direction then curving around to the direction normal to the least principal stress. The conclusions from these tests were:

1. Multiple fractures can be obtained through perforated wellbores without damaging the casing.

2. Liquid free and liquid filled wellbores exhibit the same fracture geometries.

3. Casing damage can be reduced mainly by increasing the size of the perforations and only somewhat by increasing the number of perforations.

Finally, four tests using commercial tools in liquid filled holes in the tunnel complex proved that multiple fractures can be obtained even with a large change (over an order of magnitude) in pressure loading rates. One cased and perforated wellbore, tests showed the fractures from each perforation merging a short distance from the wellbore. Figure 13 shows the fracture pattern from the four well tests. The cased and perforated wellbores showed 
fractures from each perforation and the uncased wells showed multiple, radial fracturing. This study also showed that the fracture extended only six feet above the treated zone.

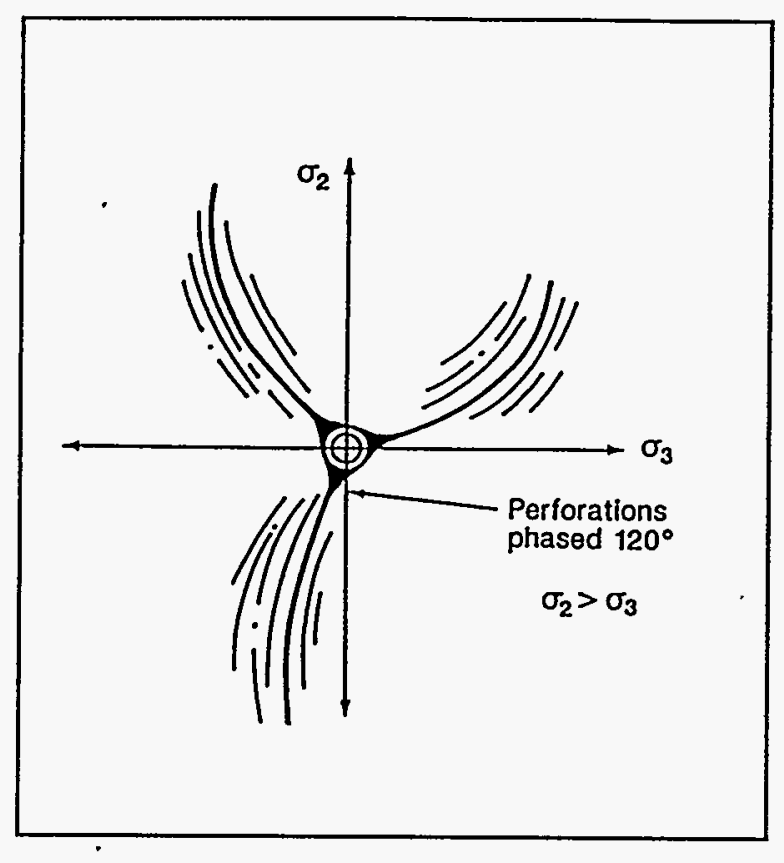

Figure 12

Fracture Pattern from a Single Mineback Experiment

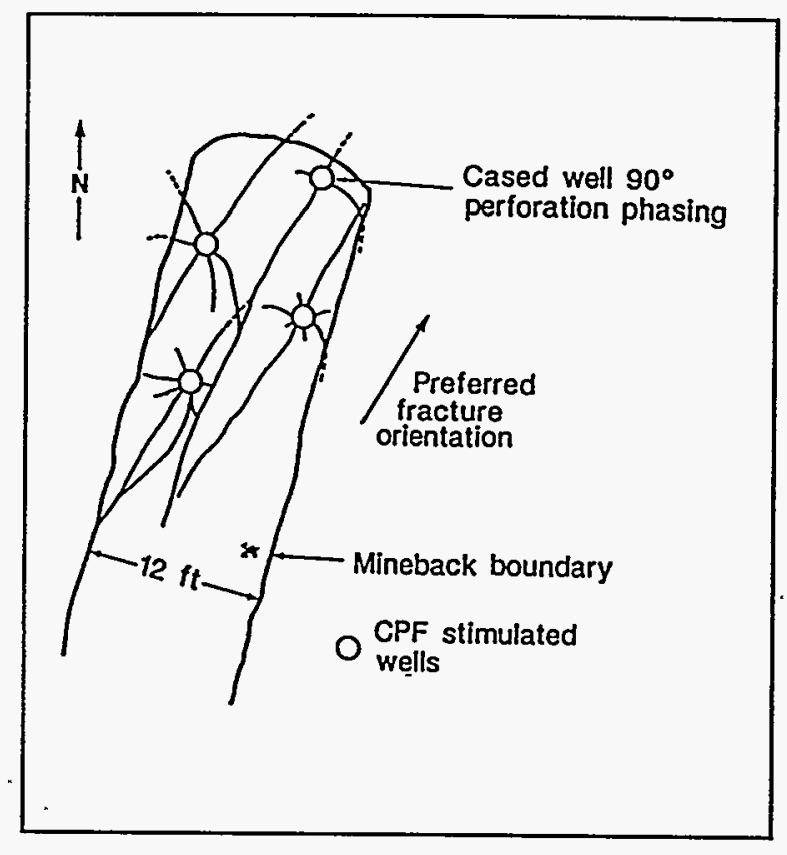

Figure 13

Fracture Patterns from Multiple Mineback Experiments

Concurrent with those field tests, laboratory studies and the development of computer models helped in the understanding of propellant fracturing concept. The most significant recent effort of this kind, sponsored by the Gas Research Institute, involved an integrated laboratory and computer modeling effort $t^{34,35}$. This work resulted in the development of a working computer simulator called PULSERAC that can predict fracture growth patterns and final geometry based on formation, wellbore and tool data. This greatly aided treatment design, implementation and post-treatment analysis.

With these tools in place, there have been numerous other published cases of the utilization of this technology for well deliverability improvement. Over one hundred such treatments were performed in open-hole, gravel-packed, slotted-liner completed thermal oil producers in the South Beldridge Field in Kern County, California ${ }^{36}$. The results of the program are illustrated in Figure 14. Despite a high percentage of wells showing no improvement in oil 
production after propellant fracturing (41\%), on average an increase of 7 barrels/day, or $58 \%$, was observed.

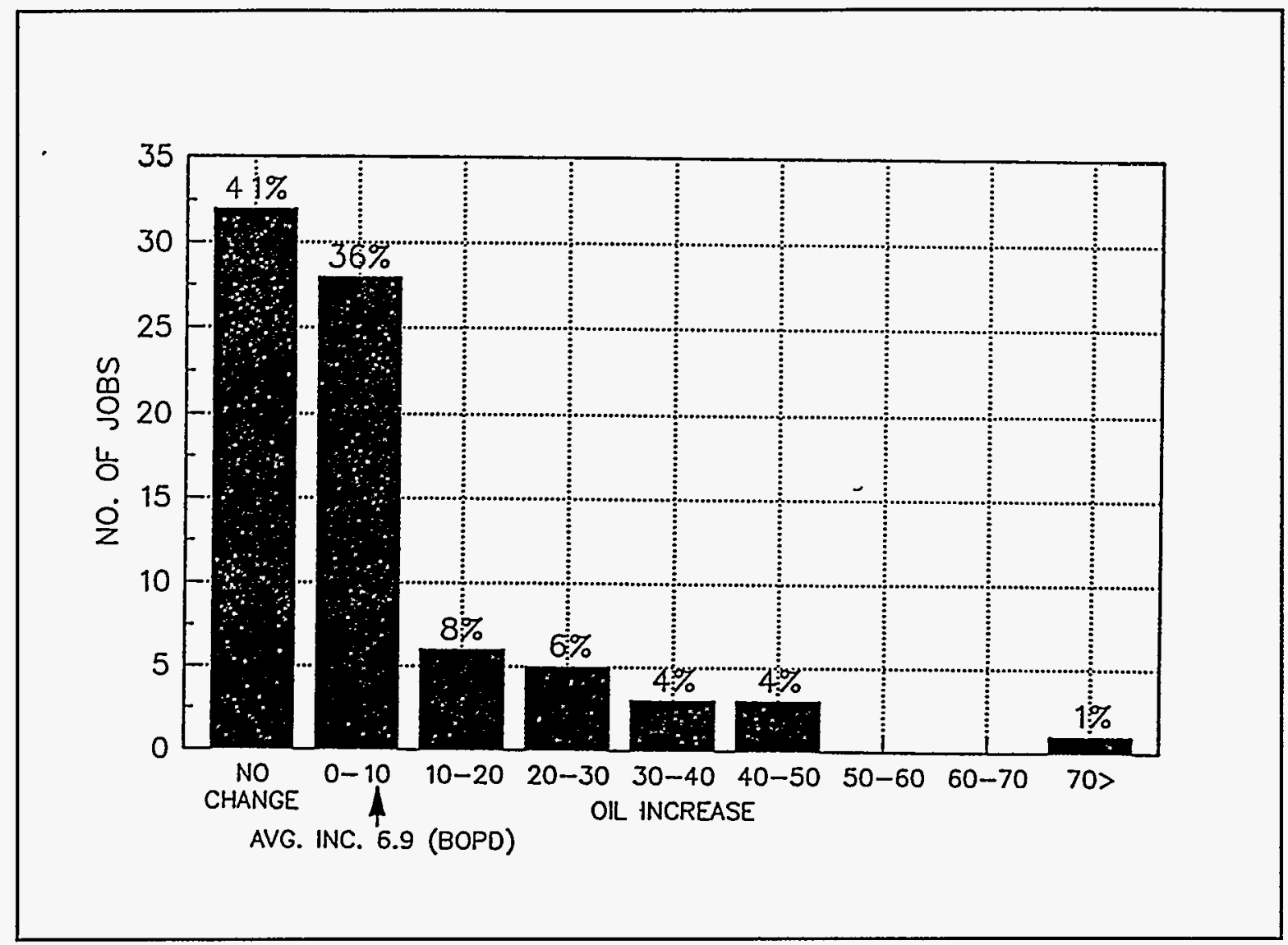

Figure 14

Production Increases Resulting from HEGF Treatments in the South Beldridge Field

Two wells were also stimulated using propellants in offshore East Lake Erie, Ontario, in $1992^{37}$. The two wells, which were cased and perforated in an over-pressured gas-bearing sandstone at a depth of 1200 feet, showed good permeability but a high degree of skin damage. The results from pre- and post-treatment pressure transient tests, shown in Table 5, suggest that propellant fracturing can be effective in cleaning up severe damage in gas wells, which is particularly relevant to this gas storage project. 
Table 5

Pre- and Post-Propellant Skin Factors from East Lake Erie

\begin{tabular}{||c|c|c|c|c|c|c||}
\hline \multirow{2}{*}{$\begin{array}{c}\text { Result/ } \\
\text { Well }\end{array}$} & \multicolumn{3}{|c|}{$\# 1$} & \multicolumn{3}{c|}{$\# 2$} \\
\cline { 2 - 4 } & \multirow{2}{*}{$\begin{array}{c}\text { Pre- } \\
\text { Frac }\end{array}$} & \multicolumn{2}{|c|}{ Post-Frac } & \multirow{2}{*}{$\begin{array}{c}\text { Pre- } \\
\text { Frac }\end{array}$} & \multicolumn{2}{|c|}{ Post-Frac } \\
\cline { 3 - 4 } \cline { 6 - 7 } & & Near & Far & & Near & Far \\
\hline \hline Permeability (md) & 28 & 40 & 12 & 29 & 37 & 4.3 \\
\hline Skin & +46 & -3.7 & -5.9 & +32 & -4.0 & -6.0 \\
\hline
\end{tabular}

\section{Application to Gas Storage}

Other than the potential for skin reduction, another reason that propellant fracturing can be considered for gas storage wells is that vertical fracture growth is limited and generally restricted to about one-half the horizontal length of the fracture. This has been confirmed in laboratory studies and by computer stimulations. The reason is that the fracture growth is gasdynamic, and there is not time nor energy available for the unrestricted height growth that can occur with a large hydraulic fracture. Therefore, knowing the distance to the reservoir cap, a propellant treatment can be designed to virtually guarantee that breakthrough will not occur.

The most obvious disadvantage of propellant technology is that the created fractures are left unpropped and hence are susceptible to closure and plugging. Therefore, to more thoroughly investigate pulse fracturing technology, pulse fracturing with nitrogen in the presence of a proppant slug across the perforations will possibly be evaluated as part of this DOE/METC RD\&D project.

\subsubsection{Pulse Fracturing with Nitrogen}

Despite its advantages, propellant gas fracturing also has application shortfalls. The loading time sequence is of short duration, 0.001 to 0.01 seconds, and a longer loading period is needed for longer, more effective fracturing. In addition, only a small volume of gas can be generated by the propellant tools due to a limited carrier capacity. It would take a larger volume 
of gas to accomplish the longer loading times and fracture lengths. Finally, the created fractures are not propped. Therefore another pulse fracturing approach, utilizing nitrogen, may have application to gas storage wells.

\section{Concept}

Pulse fracturing with nitrogen is a process similar to propellant fracturing for initiating short multi-directional fractures. This is most commonly done as part of well perforating, however it has also been used for well remediation. In the remediation procedure, a shear disk is placed in the bottom of the tubing, which is installed in the well with a packer near the perforations. Next, a predetermined volume of water, acid or other fluid is placed in the bottom of the tubing. The well is then filled with nitrogen to raise wellhead (and bottomhole) pressure to a desired level, usually to a pressure gradient far in excess of the fracture gradient, at which point the shear disk fails and the fluid slug is driven through the perforations at high rates of flow and at a bottomhole pressures far in excess of normal fracturing pressures. Multidirectional fractures are hence created. Additional nitrogen and/or fluid can be pumped after shear disk failure to help extend the created fractures.

Immediately following the treatment, the unpropped fractures will almost certainly improve well performance. However, with no proppant to hold the fracture open, it is expected that this benefit from the treatment will (at least partially) disappear with time. A variation on this process is to place a small slug of viscous, proppant carrying gel in the bottom of the well, and thus force this slurry through the perforations at high rates and pressures. The use of this process has been primarily aimed at placing resin coated sand in the perforations in sand production prone areas; , however, this should also leave a small, propped fracture outside the wellbore, thus retaining the stimulation effect for a longer time. This approach will receive attention in this DOE/METC RD\&D project. 


\section{History and Current Applications}

The advent of pulse fracturing with nitrogen as a remedial stimulation treatment can be traced to the mid-1980's, where it was attempted at DOE's Multi-Well Experiment Site ${ }^{38}$. Its true beginnings, however, were as an outgrowth of new developments in improved perforating procedures, and in particular the emergence of over-balanced perforating. Interest in overbalanced perforating, as distinctly opposite from the traditional industry approach of underbalanced perforating, originated when investigators reported that there was no difference in well performance when wells were perforated in over-balanced versus under-balanced mud ${ }^{39}$.

DOE investigated this phenomena further in its RD\&D on optimized and low-damage (non-aqueous) completion methods for the naturally fractured tight sand Mesa Verde reservoir at the Multi-Well Experimental Site. In a series of tests, DOE investigated hydraulic fracturing with straight nitrogen, perforating in an under-balanced column of nitrogen, perforating in a highly over-balanced column of nitrogen, propellant fracturing, and nitrogen pulse fracturing. Their conclusions were that perforating in a highly over-balanced column of nitrogen and nitrogen pulse fracturing were both practical and successful at achieving the desired well enhancing results.

More recently, Oryx Energy has aggressively pursued the development of this technology to improve the quality of their completions ${ }^{40}$. Out of a total of fifteen field tests, of both overbalanced perforating in nitrogen and nitrogen pulse fracturing (surging), fourteen showed negative post-job skin factors (Table 6). A number of these treatments utilized a sand slug positioned at the bottom of the well. 
Table 6

Results of Oryx Energy Nitrogen Pulse Fracturing Program

\begin{tabular}{||l|c|c|c|c|c||}
\hline \multicolumn{1}{|c|}{$\begin{array}{c}\text { Well/Site } \\
\text { Location }\end{array}$} & $\begin{array}{c}\text { Formation } \\
\text { Name/Type }\end{array}$ & $\begin{array}{c}\text { O.B. } \\
\text { Fluid } \\
\text { System }\end{array}$ & $\begin{array}{c}\text { Type } \\
\text { (Perf/ } \\
\text { Surge) }\end{array}$ & $\begin{array}{c}\text { Midperf } \\
\text { Depth } \\
\text { (ft) }\end{array}$ & $\begin{array}{c}\text { Post- } \\
\text { Treatment } \\
\text { Skin }\end{array}$ \\
\hline \hline 1. Texas & Strawn SS & N2 & Perf & 5769 & -0.6 \\
\hline 2. Texas & Strawn SS & N2 \& Sand & Perf & 5763 & -2.2 \\
\hline 3. Texas & Strawn SS & N2 \& Sand & Perf & 5763 & -2.3 \\
\hline 4. Texas & Strawn SS & N2 \& Sand & Perf & 5768 & -2.3 \\
\hline 5. Texas & Strawn SS & N2 \& Sand & Perf & 5697 & -2 \\
\hline 6. New Mexico & Atoka LS & N2 \& HCL & Perf & 14305 & -2.3 \\
\hline 7. Oklahoma & 1st Spiro SS & N2 \& HCL & Perf & 10823 & -1.4 \\
\hline 8. New Mexico & Morrow SS & N2 \& Sand & Perf & 9490 & 85 \\
\hline 9. New Mexico & Atoka SS & N2 \& ISP & Perf & 13021 & -3.3 \\
\hline 10. Texas & Strawn SS & N2 \& Sand & Perf & 5899 & -3.6 \\
\hline 11. New Mexico & Morrow SS & N2 \& ISP & Perf & 10784 & -5 \\
\hline 12. Michigan & PDC SS & N2 \& HCL & Surge & 10231 & -0.4 \\
\hline 13. Oklahoma & Red Fork SS & N2 \& Wtr & Surge & 12630 & -1.5 \\
\hline 14. Texas & Strawn SS & N2 \& Sand & Surge & 5921 & -1.1 \\
\hline 15. Oklahoma & Skinner SS & N2 \& Wtr & Surge & 11321 & -1.5 \\
\hline
\end{tabular}

\section{Application to Gas Storage}

Nitrogen pulse fracturing should be suitable for bypassing near wellbore damage in high permeability gas storage wells. A treatment could be conducted on an operational well with only a few hours of down time. It may even be possible to perform a pulse fracture treatment with injection or produced gas. Since post-treatment cleanup is not required, the treatment can be conducted during injection or production cycles. Of particular interest is the utilization of a proppant slug at the bottom of the well to prop the created fractures. This may help retain deliverability enhancement for longer periods of time. 


\subsection{Review of Recent Fracturing Experience in the Gas Storage Industry}

\subsection{Overview of Remediation Activity}

During the initial phase of this $R D \& D$ project, gas storage operators were contacted and asked if they would be interested in participating in the project by providing a fracture technology test site. Response to the solicitation was encouraging; 41 companies replied to the solicitation (representing $75 \%$ of all U.S. gas storage wells) of these, 23 companies (representing $65 \%$ of all U.S. gas storage wells) indicated an interest to participate. Of relevance to this discussion, however, is that each company was asked how many wells they remediated and how many they fractured during 1993 and 1994. Table 7 summarizes this information.

Table 7

Summary of Storage Well Remediation Activity

\begin{tabular}{|c|c|c|}
\hline & 1993 & 1994 \\
\hline Total U.S. Gas Storage Wells & \multicolumn{2}{|c|}{14,870} \\
\hline Total Wells Represented by Respondents & \multicolumn{2}{|c|}{$11,152(75 \%)$} \\
\hline Total Number of Remediation Treatments & 337 & 365 \\
\hline Total Number of Fracture Treatments & 14 & 44 \\
\hline
\end{tabular}

These data suggest several trends. Firstly, only about $3 \%$ of all storage wells are remediated on an annual basis. Of the wells remediated, only $4 \%$ involved fracturing (by 4 companies) in 1993, but that proportion increased to $12 \%$ (by 6 companies) in 1994. This suggests an increasing interest in fracturing on the part of industry to revitalize the deliverability of existing storage wells, yet overall this technology is still not widely utilized, especially considering that 30 of 44 fracture treatments conducted in 1994 were performed by one company.

A breakdown of recent fracturing experience by company is provided in Table 8 (the data is limited to those companies responding to the solicitation). One company in particular, CNG Transmission, accounts for $68 \%$ of the fracturing experience in 1994 of those companies responding to the solicitation. A description of that experience is provided later in this section. 
First, however, three case studies of non-fracturing remediation programs are presented as a basis by which to compare the fracture restimulation results.

Table 8

Storage Well Remediation Activity by Company

\begin{tabular}{|c|c|c|}
\hline Company & 1993 & 1994 \\
\hline CNG Transmission Corporation & 2 & 30 \\
\hline Columbia Gas Transmission Corporation & 9 & 5 \\
\hline Consumers Power & 1 & 1 \\
\hline Honeoye Storage Corporation & 0 & 1 \\
\hline Montana Power Company & 0 & 2 \\
\hline National Fuel & 0 & 5 \\
\hline Southern Natural Gas & 2 & 0 \\
\hline Total & 14 & 44 \\
\hline
\end{tabular}

\subsection{Non-Fracturing Remediation Case Studies}

While there exist many wells and fields which could be studied to establish the effectiveness of the more traditional, non-fracturing well revitalization methods, three recently published cases have been selected because of the type and quality of information obtained which clearly demonstrate the most important shortcomings of these approaches. The three cases are labeled as they are presented in the literature, specifically Field $A$ and Field $\mathrm{B}^{41}$, and Case $2^{42}$. In each case, specific field names, locations and storage formations were not revealed. Nevertheless, the results provide a clear picture of conventional treatment effectiveness.

\section{Field A}

A total of 12 wells were remediated in this West Virginia field using a variety of techniques including coiled-tubing cleanouts, cleanout/reperforating, and reperforating only. Pre- and post-treatment, peak-day deliverability and pressure-transient tests were performed to evaluate treatment effectiveness. The results are provided in Table 9. 
Table 9

Field A Remediation Results

\begin{tabular}{||c|c|c|c|c|c||}
\hline \multirow{2}{*}{ Well } & \multirow{2}{*}{ Treatment } & \multicolumn{2}{c|}{$\begin{array}{c}\text { Peak Day } \\
\text { Deliverability } \\
\text { (MMcfd }\end{array}$} & \multicolumn{2}{c||}{ Skin Factor } \\
\cline { 3 - 6 } & & Pre- & Post- & Pre- & Post- \\
\hline \hline 1 & Coiled Tubing Cleanout & 0.080 & 6.200 & +160.0 & +10.0 \\
\hline 2 & Coiled Tubing Cleanout & 0.425 & 13.500 & +33.0 & +3.0 \\
\hline 3 & Coiled Tubing Cleanout & 1.300 & 1.650 & +8.5 & +5.8 \\
\hline 4 & Coiled Tubing Cleanout & 2.000 & 0.900 & -2.0 & +4.4 \\
\hline 5 & Coiled Tubing Cleanout & 2.000 & 3.700 & +10.0 & +2.7 \\
\hline 6 & Coiled Tubing Cleanout & 0.115 & 0.250 & +8.7 & +5.0 \\
\hline 7 & Cleanout/Reperforate & 0.010 & 4.000 & +30.0 & +0.4 \\
\hline 8 & Cleanout/Reperforate & 4.300 & 5.200 & +2.5 & +4.7 \\
\hline 9 & Cleanout/Reperforate & 2.800 & 3.100 & +5.5 & +6.7 \\
\hline 10 & Reperforate Only & 0.800 & 1.300 & +22.0 & +22.0 \\
\hline 11 & Reperforate Only & 1.500 & 2.150 & +3.0 & +1.8 \\
\hline 12 & Reperforate Only & 3.500 & 9.000 & +732 & +854 \\
\hline \hline & Average & 1.569 & 4.246 & & \\
\hline \hline
\end{tabular}

The improvement in peak day deliverability utilizing the conventional remediation methods is significant, averaging $171 \%$. However, the pressure transient test results, providing estimates of skin both before and after the treatments, provide a more insightful interpretation. While in most cases there is clearly a reduction in skin effect, all post-remediation skin factors are still positive, suggesting the wells are still damaged and hold considerable further potential for deliverability improvement. Fracturing, which can produce highly negative skin factors, holds promise for providing these enhanced deliverabilities. 


\section{Field B}

This case consists of nine wells in a West Virginia gas storage field which were remediated using either a coiled tubing cleanout or treated water injection to remove salt. The pre- and post-treatment peak deliverability and skin factor results are given in Table 10. Similar to Field A, the treatments resulted in a favorable improvements to deliverability, averaging $46 \%$. However, examination of the post-treatment skin factor data again suggests that most wells are still damaged after the treatments, leaving an opportunity for further deliverability improvements through the application of more effective stimulation methods such as fracturing.

Table 10

Field B Remediation Results

\begin{tabular}{||c|c|c|c|c|c||}
\hline \multirow{2}{*}{ Well } & \multirow{2}{*}{ Treatment } & \multicolumn{2}{c|}{$\begin{array}{c}\text { Peak Day } \\
\text { Deliverability } \\
\text { (MMcfd) }\end{array}$} & \multicolumn{2}{c||}{ Skin Factor } \\
\cline { 3 - 6 } & & Pre- & Post- & Pre- & Post- \\
\hline \hline 1 & Coiled Tubing Cleanout & 7.700 & 16.500 & +7.0 & -2.9 \\
\hline 2 & Coiled Tubing Cleanout & 3.300 & 7.300 & +29.3 & +4.6 \\
\hline 3 & Coiled Tubing Cleanout & 0.500 & 0.550 & +14.5 & +14.8 \\
\hline 4 & Coiled Tubing Cleanout & 11.500 & 16.500 & +8.4 & +0.5 \\
\hline 5 & Coiled Tubing Cleanout & 4.800 & 8.600 & +10.6 & +3.6 \\
\hline 6 & Coiled Tubing Cleanout & 4.100 & 7.000 & +4.1 & -1.4 \\
\hline 7 & Treated Water & 26.000 & 26.000 & -3.0 & -3.1 \\
\hline 8 & Treated Water & 0.700 & 0.700 & - & +3.1 \\
\hline 9 & Treated Water & 8.000 & 14.000 & -0.9 & -2.6 \\
\hline \multicolumn{7}{|c|}{ Average } & 7.400 & 10.794 & & \\
\hline \hline
\end{tabular}


Case 2

In this case, several wells were jetted and cleaned-out using coiled tubing. The pre- and post-stimulation peak deliverability and skin factor results are provided in Table 11 . While the remediation treatments provided a $174 \%$ improvement in deliverability on average, most wells were again still damaged after the treatments. This example further confirms the results from Fields $\mathrm{A}$ and $\mathrm{B}$, and strengthens the conclusion that the remediation treatments used by industry today typically do not effectively remove all the damage to provide the best deliverability, and that further improvement, specifically that that might be provided by fracturing, are needed.

Table 11

Case 2 Remediation Results

\begin{tabular}{|c|c|c|c|c|c|}
\hline \multirow[t]{2}{*}{ Well } & \multirow[t]{2}{*}{ Treatment } & \multicolumn{2}{|c|}{$\begin{array}{c}\text { Peak Day } \\
\text { Deliverability } \\
\text { (MMcfd) }\end{array}$} & \multicolumn{2}{|c|}{ Skin Factor } \\
\hline & & Pre- & Post- & Pre- & Post- \\
\hline 1 & $\begin{array}{c}\text { Coiled Tubing Jetting } \\
\text { Cleanout }\end{array}$ & 2.541 & 11.149 & +3.6 & -1.5 \\
\hline 2 & $\begin{array}{l}\text { Coiled Tubing Jetting } \\
\text { Cleanout }\end{array}$ & 0.000 & 4.688 & - & 0.4 \\
\hline 4 & $\begin{array}{c}\text { Coiled Tubing Jetting } \\
\text { Cleanout }\end{array}$ & 0.534 & 2.749 & +77.6 & +4.0 \\
\hline 5 & $\begin{array}{l}\text { Coiled Tubing Jetting } \\
\text { Cleanout }\end{array}$ & 0.458 & 0.893 & +81.3 & +37.9 \\
\hline 6 & $\begin{array}{c}\text { Coiled Tubing Jetting } \\
\text { Cleanout }\end{array}$ & 4.180 & 5.830 & +4.6 & - \\
\hline 7 & $\begin{array}{l}\text { Coiled Tubing Jetting } \\
\text { Cleanout }\end{array}$ & 2.260 & 3.315 & +14.0 & +3.0 \\
\hline 8 & $\begin{array}{c}\text { Coiled Tubing Jetting } \\
\text { Cleanout }\end{array}$ & 1.194 & 2.024 & +16.1 & +14.1 \\
\hline & Average & 1.595 & 4.378 & & \\
\hline
\end{tabular}




\subsection{Fracturing Case Study in the Gas Storage Industry}

Having reviewed several examples of remediation projects using traditional workover approaches in the storage industry, and their effectiveness, one case where fracturing was utilized is presented. This, drawn from the 1994 experience of CNG Transmission, illustrates the effectiveness of fracturing.

In 1994, CNG Transmission Corporation fracture-stimulated 30 wells in five Oriskany gas storage fields in Pennsylvania and New York (Table 12) ${ }^{43}$.

Table 12

CNG Transmission Gas Storage Fields Where Fracturing Was Utilized in 1994

\begin{tabular}{||l|c|c||}
\hline \multicolumn{1}{|c|}{ Field } & State & No. Wells Fractured \\
\hline \hline Greenlick & Pennsylvania & 12 \\
\hline Sabinsville & Pennsylvania & 7 \\
\hline Woodhull & New York & 5 \\
\hline Leidy & Pennsylvania & 3 \\
\hline Tioga & Pennsylvania & 3 \\
\hline \hline
\end{tabular}

The treatments utilized 18,000-19,000 gallons of cross-linked gel and 16/30 sand volumes of 20,000 - 30,000 pounds, which were pumped at maximum concentrations of 3-4 lbs/gal. Preand post-treatment deliverability data were collected on twelve wells, the results of which are presented in Table 13. 
Table 13

Results of Fracture Stimulation Treatments

\begin{tabular}{|c|c|c|c|c|c|}
\hline $\begin{array}{l}\text { Well } \\
\text { Name } \\
\end{array}$ & Fíeld & $\begin{array}{l}\text { Pre-Frac } \\
\text { Deliyerability } \\
\text { (MMcfd) }\end{array}$ & $\begin{array}{l}\text { Post-Frac } \\
\text { Deliverability } \\
\text { (MMcfd) }\end{array}$ & $\begin{array}{l}\text { Folds of } \\
\text { Iricrease } \\
\because\end{array}$ & Remarks $\quad \cdots$ \\
\hline LW-5 & Liedy & 1.27 & 12.18 & 9.60 & \\
\hline LW-902 & Liedy & 4.88 & 23.43 & 4.80 & \\
\hline RW-37 & Greenlick & 1.93 & 2.02 & 1.05 & Previously Fracture-Stimulated \\
\hline $\mathrm{RW}-49$ & Greenlick & 1.98 & 2.59 & 1.31 & Previously Fracture-Stimulated \\
\hline RW-44 & Greenlick & 2.93 & 9.82 & 3.35 & Previously Fracture-Stimulated \\
\hline $\mathrm{RW}-46$ & Greenlick & 3.77 & 32.12 & 8.52 & Previously Fracture-Stimulated \\
\hline RW-504 & Greenlick & 9.32 & 59.05 & 6.33 & Previously Fracture-Stimulated \\
\hline$R W-501$ & Greenlick & 5.16 & 33.24 & 6.44 & \\
\hline $\mathrm{RW}-502$ & Greenlick & 5.41 & 12.84 & 2.37 & Previously Fracture-Stimulated \\
\hline RW-503 & Greenlick & 5.33 & 44.73 & 8.39 & Previously Fracture-Stimulated \\
\hline RW-58 & Greenlick & 2.08 & 3.04 & 1.46 & Previously Fracture-Stimulated \\
\hline \multirow[t]{2}{*}{ TW-500 } & Tioga & 0.30 & 7.07 & 23.56 & \\
\hline & Average & 3.70 & 20.20 & 5.46 & \\
\hline
\end{tabular}

On average, these stimulation treatments provided a $450 \%$ improvement in well deliverability. Interestingly, eight of the twelve wells had been previously fracture-stimulated. For these wells, the average deliverability was four-fold, whereas it was over a full order of magnitude for the unstimulated wells.

While pre- and post-treatment pressure transient tests were unavailable to determine how effective the post-fracturing completion is, an average $450 \%$ improvement in well deliverability considerably exceeds the improvement observed with any of the non-fracturing remediation cases discussed earlier. This begins to suggest the vast potential fracturing holds for improving the deliverability of gas storage wells. The need to better demonstrate the effectiveness of fracturing for gas storage wells is the guiding principle of this DOE/METC RD\&D project. 


\title{
4.0 Conclusions
}

Based on the information presented in this report, our conclusions regarding the potential for new and novel fracture stimulation technologies to enhance the deliverability of gas storage wells are as follows:

\begin{abstract}
New and improved gas storage well revitalization methods have the potential to save industry on the order of $\$ 20-25$ million per year by mitigating deliverability decline and reducing the need for costly infill wells
\end{abstract}

- Fracturing technologies have the potential to fill this role, however operators have historically been reluctant to utilize this approach due to concerns with reservoir seal integrity. With advanced treatment design tools and methods, however, this risk can be minimized.

- Of the three major fracturing classifications, namely hydraulic, pulse and explosive, two are believed to hold potential to gas storage applications (hydraulic and pulse). Five particular fracturing technologies, namely tip-screenout fracturing, fracturing with liquid carbon dioxide, and fracturing with gaseous nitrogen, which are each hydraulic methods, and propellant and nitrogen pulse fracturing, which are both pulse methods, are believed to hold potential for gas storage applications and will possibly be tested as part of this project.

- $\quad$ Field evidence suggests that, while traditional well remediation methods such as blowing/washing, mechanical cleaning, etc. do improve well deliverability, wells are still left damaged afterwards, suggesting that considerable room for further deliverability enhancement exists. Limited recent trials of hydraulic fracturing imply that this approach does in fact provide superior deliverability results, but further RD\&D work is needed to fully evaluate and demonstrate the benefits and safe application of this as well as other fracture stimulation technologies. 


\section{References}

1. "The Potential for Natural Gas in the United States", 1992, Washington, D.C.: National Petroleum Council.

2. "Survey of Gas Storage Facilities in the United States and Canada", 1993, Arlington, VA: American Gas Association, Operating Section Report.

3. "State of Technology Assessment and Evaluation of Gas Storage Well Productivity Techniques", 1993, Maurer Engineering, Inc. and T. Joyce Associates, Inc., GRI 93/0001, December.

4. Nolte, K.G. and Smith, M.B., 1981, "Interpretation of Fracturing Pressures", Journal of Petroleum Technology, Vol. 33, pp 1767, September.

5. Smith, M.B., 1981, 1985, "Stimulation Design for Short, Precise Hydraulic Fractures", SPE 10313, SPE Annual Technical Conference, San Antonio, October 5 to 7; Society of Petroleum Engineers Journal: pp. 371-379, June 1985.

6. Smith, M.B.; Miller, W.K.; Haga, J., 1984, 1985, 1987, "Tip Screenout Fracturing: A Technique for Soft, Unstable Formations", SPE 13273, SPE Annual Technical Conference, Houston, TX, September 16 to 19; SPE California Regional Meeting, Bakersfield, CA, March 27 to 29, (pp. 893-902); SPE Production Engineering: 2(2)95103, May.

7. Hanna, B.; Ayoub, J.; Cooper, B., 1992, "Rewriting the Rule for High-Permeability Stimulation", Oilfield Review: 4(4)18-23, October.

8. Martins, J.P., Collings, P.J., Rylance, M., Et al., 1992, "Small, Highly Conductive Fractures Near Reservoir Fluid Contacts: Application to Prudhoe Bay," SPE 24856, SPE 67th Annual Technical Conference and Exhibition, Washington, D.C., October 4-7. (pp. 933-944)

9. Marcinew, R.P.; Brady, B.H.; Burynuik, S.A.; Et al., 1992, "Achieving Effective Fractures Within High-Permeability Soft Formations", Volume 2, 21st Annual Indonesian Petroleum Association Convention, Jakarta, Indonesia, October 6 to 8. (pp. 199-218)

10. Monus, F.L.; Broussard, F.W.; Ayoub, J.A.; Et al., 1992, "Fracturing Unconsolidated Sand Formations Offshore Gulf of Mexico", SPE 24844, SPE Annual Technical Conference, Washington, DC, October 4 to 7. (pp. 817-831)

11. Wong, G.K., Fors, R.R., Casassa, J.S., Et al., 1993, "Design, Execution, and Evaluation of Frac and Pack Treatments in Unconsolidated Sand Formations in the Gulf of Mexico," SPE 26563, SPE 68th Annual Technical Conference and Exhibition, Houston, TX, October 3-6. (pp. 491-506) 
12. Meese, C.A.; Mullen, M.E.; Barree, R.D., 1994, "Offshore Hydraulic Fracturing Technique", Journal of Petroleum Technology (JPT): 46(4)226-229, March.

13. Roodhart, L.P.; Fokker, P.A.; Davies, D.R.; Et al., 1994, "Frac-and-Pack Stimulation: Application, Design, and Field Experience", Journal of Petroleum Technology (JPT): 46(3)230-238, March 1994.

14. Papinczak, A.; and Miller, W.K., 1993, "Fracture Treatment Design to Overcome - Severe Near-Wellbore Damage in a Moderate Permeability Reservoir, Mereenie Field, Australia", SPE 25379, SPE Asia Pacific Oil and Gas Conference, Singapore, February 8 to 10 . (pp. 537-553)

15. Dusterhoft, R.G.; and Chapman, B.J., 1994, "Fracturing High-Permeability Reservoirs Increases Productivity", Oil \& Gas Journal: 92(25)40-44, June 20.

16. King, S.R., 1983, "Liquid $\mathrm{CO}_{2}$ for the Stimulation of Low-Permeability Reservoirs", SPE/DOE 11616, SPE/DOE Symposium on Low Permeability, Denver, CO, March 14 to 16 . (pp. 145-151)

17. Lancaster, G.; and Sinal, M.L., 1986, "Liquid $\mathrm{CO}_{2}$ Fracturing Advantages and Limitations", Paper No. 86-37-69, Volume 2, 37th Annual CIM Petroleum Society Technical Meeting, Calgary, Canada, June 8 to 11. (pp. 425-435)

18. Lillies, A.T.; and King, S.R., 1982, "Sand Fracturing with Liquid Carbon Dioxide", SPE 11341, SPE Product Technology Symposium, Hobbs, NM, November 8-9.

19. Yost, A.B.; Mazza, R.L.; Gehr, J.B., 1993, " $\mathrm{CO}_{2} /$ Sand Fracturing in Devonian Shales", SPE 26925, SPE Eastern Regional Conference, Pittsburgh, PA, November 2 to 4. (pp. 353-362)

20. "Analysis of Production Response to $\mathrm{CO}_{2}$ /San Fracturing: A Case Study"; 1994, SPE Eastern Regional Conference.

21. Harper, T.R.; Hagan, J.T.; Martins, J.P., 1985, "Fracturing Without Proppant", SPE 13858, SPE/DOE Low Permeability Gas Reservoirs, Denver, CO, May 19-22. (pp. 8394)

22. Ghauri, W.K., "Results of Well Stimulation by Hydraulic Fracturing and High Rate Oil Backflushing", Journal of Petroleum Technology, June 1980.

23. Lambert, S.W., and Trevits, M.A., "The Feasibility of No-Proppant Stimulations to Enhance Removal of Methane From the Mary Lee Coalbed", U.S. Department of Energy Report of Investigation, April, 1980.

24. Mahoney, J.V., Stubbs, P.B., Schwerer, Et al., 1980, "Effects of a No-Proppant Foam Stimulation Treatment on a Coal Seam Degasification Borehole", SPE/DOE 8931, 
SPE/DOE Symposium on Unconventional Gas Recovery, Pittsburgh, PA, May 18-21. (pp. 65-72)

25. Abel, J.C., 1981, "Application of Nitrogen Fracturing in the Ohio Shale", SPE 10378, SPE Eastern Regional Meeting, Columbus, OH, November 4 to 6. (pp. 189-197)

26. Freeman, E.R.; Abel, J.C.; Kim, C.M.; Et al., 1983, "A Stimulation Technique Using Only Nitrogen", Journal of Petroleum Technology, December.

27. Gottschling, J.C.; Royce, T.N.; Shuck, L.Z., 1985, "Nitrogen Gas and Sand: A New Technique for Stimulation of Devonian Shale", Journal of Petroleum Technology:37(5)901-907, May.

28. Hunt, W.C.; and Shu, W.R., 1989, "Controlled Pulse Fracturing for Well Stimulation", SPE 18972, SPE Joint Rocky Mountain Regional/Low Permeability Reservoirs Symposium, Denver, CO, March 6 to 8. (pp. 445-450)

29. Warpinski, N.R., Schmidt, R.A., Cooper, P.W., Et al., 1979, "High Energy Gas Frac: Multiple Fracturing in a Wellbore", Proceedings of 20th U.S. Symposium of Rock Mechanics, Austin, TX. (pp. 143-152)

30. Schmidt, R.A., 1980, "In Situ Evaluation of Several Tailored-Pulse Well-Shooting Concepts," SPE/DOE 8934, SPE/DOE Symposium on Unconventional Gas Recovery, Pittsburgh, PA May 18-21. (pp. 105-110)

31. Cuderman, J.F., and Northrup, D.A., 1984, "A Propellant Based Technology for Multiple Fracturing Wellbores to Enhance Gas Recovery: Application and Results in Devonian Shale", SPE/DOE/GRI 12838, SPE/DOE/GRI Unconventional Gas Recovery Symposium, Pittsburgh, PA, May 13-15. (pp. 77-86)

32. Smith, K.T. and Schmid, J.C., 1984, "Application of an Alternate Stimulation Method for the Ferguson Sandstone in the Powder River Basin", SPE 12902, SPE Rocky Mountain Regional Meeting, Caspar, WY. (pp. 95-102)

33. Cuderman, J.F., 1986, "Tailored-Pulse Fracturing in Cases and Perforated Boreholes", SPE 15253, SPE Unconventional Gas Technology Symposium, Louisville, KY, May 18 to 21 . (pp. 525-534)

34. Hanson, J.M.; Schmidt, R.A.; Cooley, C.H.; Et al., 1984, "Multiple Fracture Stimulation Using Controlled Pulse Pressurization", SPE/DOE/GRI 12839, SPE/DOE/GRI Unconventional Gas Recovery Symposium, Pittsburgh, PA, May 13 to 15. (pp. 87-94)

35. Schatz, J.F.; Zeigler, B.J.; Hanson, J.M.; Christianson, M.C.; Et al., 1989, "Laboratory, Computer Modeling, and Field Studies of the Pulse Fracturing Process", SPE 18866, SPE Production Operations Symposium, Oklahoma City, March 13 to 14. (pp. 375-380) 
36. Fram, J.H., 1991, "Dynamic Gas Pulse Loading Stimulations of Thermal Producers at South Belridge Field, Kern County, California", SPE 21545, SPE International Thermal Operations Symposium, Bakersfield, CA, February 7 to 8. (pp. 211-216)

37. Schatz, J.F. and Czychun, A., "Formation Damage Cleanup by Dynamic Pulse Fracturing: Case Study in Permeable Gas Sands, Poster Session No. 3", SPE International Symposium on Formation Damage Control, Lafayette, LA, February 26 to 27, 1992. [abstract only]

38. Branagan, P.T. and Wilmer, R.H., 1988, "Breakdown Procedures Designed to Minimize Naturally Fractured Reservoir Damage", SPE 17716, SPE Gas Technology Symposium, Dallas, TX, June 13 to 15.

39. Bundy, T.E. and Elmer, M.J., 1987, "Perforating a High-Pressure Gas Well in Mud: Is It Really That Bad," SPE 16894, SPE Annual Technical Conference, Dallas, TX, September 27-30.

40. Handren, P.J.; Jupp, T.B.; Dees, J.M., 1993, "Overbalance Perforating and Stimulation Method for Wells", SPE 26515, SPE Annual Technical Conference, Washington, DC, October 4 to 7. (pp. 87-96)

41. Maddox, T.L. and Sikorski, D.L., 1994, "Evaluation and Development of a Deliverability Improvement Program for Gas Storage", SPE 29160, SPE Eastern Regional Conference and Exhibition, November 8-10, Charleston, WV. (pp. 41-50)

42. Fowler, H. and Holcombe, D., 1994, "Coiled Tubing Applications for Underground Gas Storage", SPE 29162, SPE Eastern Regional Conference and Exhibition, November 8-10, Charleston, WV. (pp. 57-65)

43. Stiles, E.K. and Reese, R.R., "Case Study: Hydraulic Fracturing with Cross-Linked Gels in the Oriskany Formation to Improve Gas Storage Deliverability", SPE 31003, SPE Eastern Regional Conference and Exhibition, September 18-20, Morgantown, WV. (pp. 197-207). 